\title{
MONEY, PRICES, INTEREST RATES AND THE BUSINESS CYCLE
}

\begin{abstract}
Robert G. King and
Abstract - The mechanisms governing the relationship of money, prices and interest rates to the business cycle are the most studied and most disputed topics in macroeconomics. In this paper, we first document key empirical aspects of this relationship. We then ask how well three benchmark rational expectations macroeconomic models - a real business cycle model, a sticky price model and a liquidity effect model-account for these central facts. While the models have diverse successses and failures, none can account for the fact that real and nominal interest rates are "inverted leading indicators" of real economic activity. That is, none of the models captures the post-war U.S. business cycle fact that a high real or nominal interest rate in the current quarter predicts a low level of real economic activity two to four quarters in the future.
\end{abstract}

\section{Introduction}

$\mathrm{T}$ HE positive correlation of monetary aggregates and real economic activity over the course of many business cycles is a key empirical fact about the U.S. economy. Indeed, the dynamic dimension of this covariation is so strong and stable that a monetary variable has long been included in the Commerce Department's Index of Leading Economic Indicators. While this pattern of cyclical comovement is widely agreed upon, its interpretation is not. Some macroeconomists view money as purely passive, with a positive response to varying levels of economic activity producing the positive correlation. Others view changes in the quantity of money as an important, perhaps dominant, source of economic fluctuations. Frequently, the real effects of monetary changes are suggested to arise from frictions in commodity, labor or financial markets. In economic theories that describe the influence of these frictions, the transmission mechanism from monetary changes to real activity is typically viewed as involving interest rates and the price level.

The primary goal of this paper is to evaluate three models that explain the link between money, prices, interest rates and the business cycle. We do this in three steps. First, we document the cyclical behavior of these variables in the United States over the postwar period. Second, we construct three quantitative rational expectations models of macroeconomic activity: (i) a real business cycle model with endogenous money; (ii) a model of commodity market frictions with monetary non-neutralities arising from gradual adjustment of goods prices; and (iii) a model of financial market frictions with monetary non-neutralities arising from gradual adjustments of portfolios. Finally, we compare the models' prediction for the business cycle behavior of money, prices and interest rates with the data.

Received for publication December 9, 1994. Revision accepted for publication July 12, 1995.

*University of Virginia and Federal Reserve Bank of Richmond; and Princeton University, respectively.

This paper has benefited from constructive comments by Lucrezia Reichlin, Ken West and a referee. Support was provided by the National Science Foundation through grants NSF-91-22963 and SBR-94-09629.
In exploring the predictions of these models, we take the stock of money to be one of several exogenous variables in the system. All of our models are capable of generating a forecasting role for money relative to real economic activity, similar to that found in the U.S. data. In the real business model, monetary changes can forecast real activity because productivity is related to many underlying sources of shocks and because these real shocks also affect the money stock. In the models with "sticky prices" and "liquidity effects" (short-hand names for the models with frictions in the commodity and financial markets), monetary changes have an additional direct positive effect on aggregate output.

The outline of the paper is as follows. Section II describes the data and documents its business cycle characteristics. Section III outlines the three macroeconomic models and develops the particular quantitative versions of the models used in our analysis. Our main empirical results are presented in section IV, and section V summarizes our results and concludes.

\section{Features of Post-War U.S. Business Cycles}

Throughout this paper we use a data set consisting of output, consumption, investment, employment, prices, wages, the money supply and interest rates. Output is private net national product, less housing and farming. We abstract from government, housing and farming because of problems in measuring these sectors' inputs and output. Prices are the implicit price deflator for this measure of output. Consumption is nondurable plus service consumption. Investment is nonresidential fixed investment. Labor input is private nonagricultural employee hours. Real wages are compensation per hour for the nonfarm business sector divided by the output deflator. Money is the M1 aggregate. The nominal interest rate is the rate on three month Treasury bills. The data for output, consumption, investment, employment and money are per capita. ${ }^{1}$ We will let $y, c, i, n, M$ and $M-P$ denote the per capita values of output, consumption, investment, employment, money and real balances; $P$ will denote the price level; $w$ will denote the real wage; finally, $R$ and $r$ will denote the level of nominal and real interest rates.

\footnotetext{
${ }^{1}$ All variables are from Citibase, unless otherwise noted. The precise definitions, using Citibase labels are: output $=(g d p q-g p b f q-g b u h q-g g n p q) / p 16$; price deflator $=(g d p-g p b f-g b u h-g g n p) /(g d p q-g p b f q-g b u h q-g g n p q)$; consumption $=(g c n q+g c s q) / p 16 ;$ investment $=g i n q / p 16 ;$ employment $=l p m n u /$ $p 16$; real wages $=l b c p u /$ price deflator; money $=f m 1 / p 16(1959-1992)$ and authors' calculation (see King, Plosser, Stock and Watson (1991) for 19471958); nominal interest rates $=$ fygm 3 ; real interest rates $=$ fygm $3-$ $\left.400 * E_{t}\left(p_{t+1}\right)-p_{t}\right)$, where the forecast of inflation is calculated from the VAR described in footnote 13 below.
} 


\section{A. Business Cycle Variability}

The power spectrum of the growth rates of macroeconomic variables provides important information about the nature of business cycles; figure 1 presents the estimated spectra for the growth rates of $y, M, P$ and $M / P$ as well as the spectra of the levels of $R$ and $r^{2}$ (Growth rates are measured in percentage points at annual rate, i.e., as 400 times the first differences of the logarithms of the variables.)

1. The Spectral Shape of Output Growth: The power spectrum of output is shown in panel A of figure 1. The distinctive spectral shape in panel $A$ is typical of the growth rate spectra of a wide range of real macroeconomic variables. (This is documented in King and Watson (1995a).) In particular, these growth rate spectra have the following broad features: the power spectrum is relatively low at low frequencies (a small number of cycles per period), rises to a peak at a cycle length of about 20-40 quarters and then declines at very high frequencies. We call this pattern "the typical spectral shape of growth rates." It is notably different from the typical spectral shape that Granger (1966) identifies for the levels of many economic time series, in which much of the power occurs at very low frequencies (evident in the spectra of the level of nominal interest rates in figure 1). ${ }^{3}$

To interpret the typical spectral shape of growth rates, it is useful to briefly review some key elements of time series analysis in the frequency domain. A covariance stationary variable $x_{t}$ can be decomposed into an integral of periodic components:

$$
\begin{aligned}
x_{t} & =\int_{0}^{\pi} x_{t}(\omega) d \omega \\
& =\int_{0}^{\pi}[a(\omega) \cos (\omega t)+b(\omega) \sin (\omega t)(d \omega)]
\end{aligned}
$$

where $a(\omega)$ and $b(\omega)$ are uncorrelated random variables with mean zero and common variance $2 s(\omega)$. Accordingly, the variance can be decomposed as:

$$
\operatorname{var}\left(x_{t}\right)=2 \int_{0}^{\pi} s(\omega) d \omega
$$

where the power spectrum $s(\omega)$ is the contribution to variance at frequency $\omega$. Thus, the height of the spectrum in fig-

\footnotetext{
${ }^{2}$ These spectra are calculated from an estimated VAR that will be described in detail in footnote 13 below. Estimated spectra for the other variables (consumption, investment, employment, and real wages) are presented in King and Watson (1995a). Standard errors for the estimated spectra are large, approximately equal to $35 \%$ of the value of the spectrum. This estimated value was determined by simulation, and is roughly equal to the proportionality factor for the asymptotic distribution of autoregressive spectral estimators given in Berk (1974, Theorem 6), i.e., $(2 k / T)$ where $k$ is the lag length and $T$ is the sample size.

${ }^{3}$ Our description of the low frequency character of the growth rate spectrum is dependent on the spectral estimator that we employ. Our estimator imposes cointegration between consumption, investment and output, and this forces their growth rates to have identical spectral mass at frequency zero. Estimates of the spectrum of output constructed from low-order, univariate AR models have a peak at frequency zero. This issue is discussed in more detail in King, Plosser, Stock and Watson (1991) and Cochrane (1993). By contrast, the business cycle character of the growth rate spectra is robust to the spectral estimator used.
}

ure 1 at cycles per period $\omega / 2 \pi$ indicates the extent of that frequency's contribution to the variance of the growth rate.

A conventional frequency domain definition of business cycles is that these are frequencies between six and thirty-two quarters: this definition derives from the duration of business cycles isolated by NBER researchers using the (non-spectral) methods of Burns and Mitchell (1946). Thus, in each of the panels in figure 1 we show two vertical lines, which correspond to frequencies between $0.03=1 / 32$, and $0.16=1 / 6$ cycles per period. Looking at panel $A$, two features of the spectrum stand out. First, the business cycle interval contains the peak in the spectrum. Second, the business cycle interval contains the bulk of the variance of output growth (specifically $58 \%$ ).

This spectral shape of output growth has played an important role in the conclusions of earlier authors about the nature of business cycles. For example, there has been much interest in univariate models of the consequences of "stochastic trends" for economic fluctuations. ${ }^{4}$ This spectral shape has important implications for empirical conclusions of this research. Following Watson (1986), this can be seen by considering the frequency domain interpretation of the trendcycle decomposition suggested by the work of Beveridge and Nelson (1981). For this purpose, let $y_{t}$ be the stochastic components of the logarithm of output and let it be decomposed as follows:

$$
y_{t}=y_{t}^{\tau}+y_{t}^{c}
$$

where $y_{t}^{\tau}$ and $y_{t}^{c}$ are the trend and cyclical components of output, respectively. Without further assumptions, this decomposition is not operational, but it can be made so by requiring that the trend is a random walk, $y_{t}^{\tau}=y_{t-1}^{\tau}+\epsilon_{t}^{\tau}$ and the cyclical component is stationary. Under these assumptions, the variance at frequency $\omega$ of $\Delta y_{t}$ can be determined from the spectral decomposition

$$
\begin{aligned}
s_{\Delta y}(\omega)= & \operatorname{var}\left[\Delta y_{t}^{\tau}(\omega)\right]+\operatorname{var}\left[\Delta y_{t}^{c}(\omega)\right] \\
& +2 \operatorname{cov}\left[\Delta y_{t}^{\tau}(\omega), \Delta y_{t}^{c}(\omega)\right] .
\end{aligned}
$$

Since the trend is assumed to be a random walk, it follows that $\Delta y_{t}^{\tau}=\epsilon_{t}^{\tau}$, i.e., that $\operatorname{var}\left(\Delta y_{t}^{\tau}(\omega)\right)$ is constant across all frequencies. Second, since the cyclical component is stationary, its first difference has no component at frequency zero so that the height of the spectrum at the origin determines the variance of $\Delta y_{t}^{\tau}(\omega)$. However, a decomposition at other frequencies cannot be made without additional identifying assumptions.

The restriction employed by Watson (1986) is that $\operatorname{cov}\left(\Delta y_{t}^{\tau}(\omega), \Delta y_{t}^{c}(\omega)\right)=0$ at all frequencies. In this case, the shape of the power spectrum has an immediate and strong implication: there is only a small trend contribution to growth

\footnotetext{
${ }^{4}$ References include Campbell and Mankiw (1987), Cochrane (1988) and Nelson and Plosser (1982). Similar issues are discussed with the help of multivariate models in Cochrane (1994), Fama (1993), King, Plosser, Stock and Watson (1991) and Rotemberg and Woodford (1994).
} 
Figure 1. - Growth Rate SPectra: Postwar Quarterly Data For the UNITED STATES
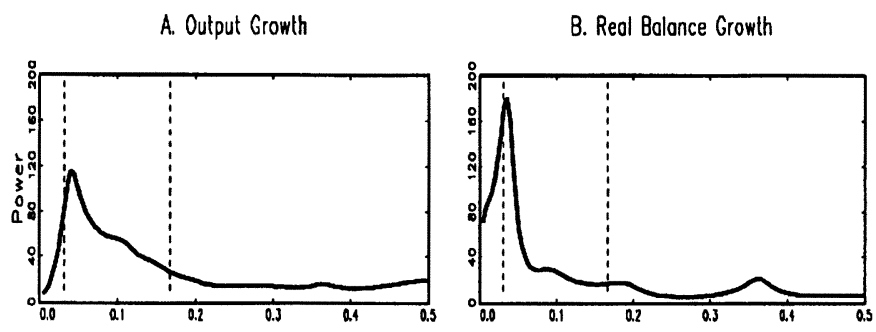

C. Noney Supply Growth

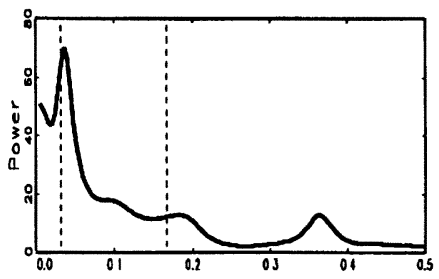

E. Nominol Interest Rotes
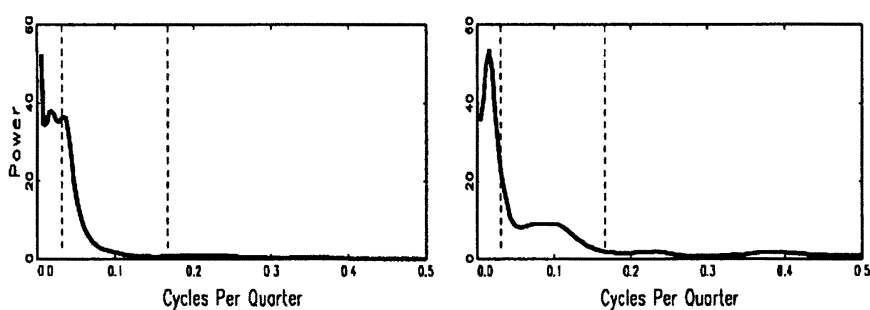

Note: Vertical lines denote frequencies corresponding to 6 and 32 quarters.

rates (given by the height of the spectrum at frequency zero) and the remainder of the variability arises from highly persistent, but ultimately temporary, variations in $\Delta y_{t}^{c}$. Further, the hump shape of the power spectrum indicates that there is substantial predictability of the cyclical component of output growth, a result developed in detail in Rotemberg and Woodford (1994) using time domain methods. As those authors stress, this interpretation of the spectral shape for the growth rate of output suggests the need for business cycle models with highly persistent, but ultimately temporary, components. Potentially, such models involve the persistent, but ultimately, neutral effects of nominal variables on real output.

One criticism of this interpretation of the typical growth rate spectral shape is that real business cycle models do not imply that $\operatorname{cov}\left(\Delta y_{t}^{\tau}(\omega), \Delta y_{t}^{c}(\omega)\right)=0$ when they are driven by random walk productivity shocks. Indeed, it is the essence of these models that permanent changes in technology set off "transitional dynamics" in which there is a high amplitude response of investment (an "overshooting" relative to its longrun level) and transitory variation in labor input. However, Watson (1993) documents that the spectrum of output growth in a standard $\mathrm{RBC}$ model with a random walk productivity shock does not display the "typical spectral shape of growth rates," suggesting either that the model's real shocks must contain significant transitory components (or mean reversion) or that other transitory shocks must affect output.
2. Spectra of Other Variables: Spectra of real balances, money, prices and interest rates are shown in panels B-F of figure 1 . There are three characteristics of these spectra that are suggestive about the potential role of nominal variables in the business cycle. First, we see the typical spectral shape in both real and nominal money growth (panels $\mathrm{B}$ and $\mathrm{C}$ ). The substantial business cycle variability of money growth suggests that variations in money may be an important source of economic fluctuations, leading to the typical spectral shape in the growth rates of other variables. Second, we see the typical spectral shape in price inflation (panel D), but with a peak at a lower frequency: it occurs at a periodicity of 51 quarters rather than 20 quarters. This suggests some smoothing of nominal money in prices, i.e, some gradual adjustment of prices. Finally, the spectra of money growth and price inflation have a higher variability at very low frequencies than do real variables: their low frequency components have standard deviations in the $7 \%-8 \%$ range, while the standard deviation of output is approximately $3 \%$. This finding suggests the existence of stochastic trend components in nominal variables that are independent from those in real variables.

Real and nominal interest rates have relatively more low frequency variability than the other variables, with nominal rates having Granger's typical spectral shape. Thus, most of the variability in these variables is associated with highly persistent components with a large standard deviation. (The average standard deviation is approximately 6 percentage points for components with period greater than 32 quarters.)

\section{B. Business Cycle Covariability}

We explore the patterns of comovement between real and nominal variables over the business cycle in two ways. First, table 1 presents the correlations and selected autocorrelations of the variables calculated from the estimated spectral density matrix, but using only the business cycle (6-32 quarter) frequencies. ${ }^{5}$ Second, figure 2 plots the business cycle components of the logarithms of output, employment, money and prices as well as the level of interest rates. These are formed by using an approximate band pass filter to extract the portion of the series associated with cycles of length 6-32 quarters. ${ }^{6}$ As a reference, each panel of the figure includes the NBER business cycle reference dates and a plot of output.

We stress three empirical characteristics of the interaction between money, prices, interest rates and output that are important for our subsequent analysis. First, both nominal

\footnotetext{
${ }^{5}$ In terms of the spectral representation in (1), this table shows the correlation of the series constructed as:

$$
x_{t}=\int_{\omega_{1}}^{\omega_{2}}[a(\omega) \cos (\omega t)+b(\omega) \sin (\omega t)] d \omega
$$

with $\omega_{1}$ and $\omega_{2}$ representing the business cycle frequencies and $x_{t}$ representing the log-level of the relevant series.

${ }^{6}$ The series are formed by passing the data through a symmetric two-sided filter with 12 leads and lags. The filter weights are chosen to produce an optimal $\left(L^{2}\right)$ approximation to the exact 6-32 quarter band pass filter, subject to the constraint the filter has zero gain at frequency 0. See Baxter and King (1995).
} 
TABLE 1. - Characteristics OF Business CyCle CoMPonents OF POSTWAR U.S. DATA

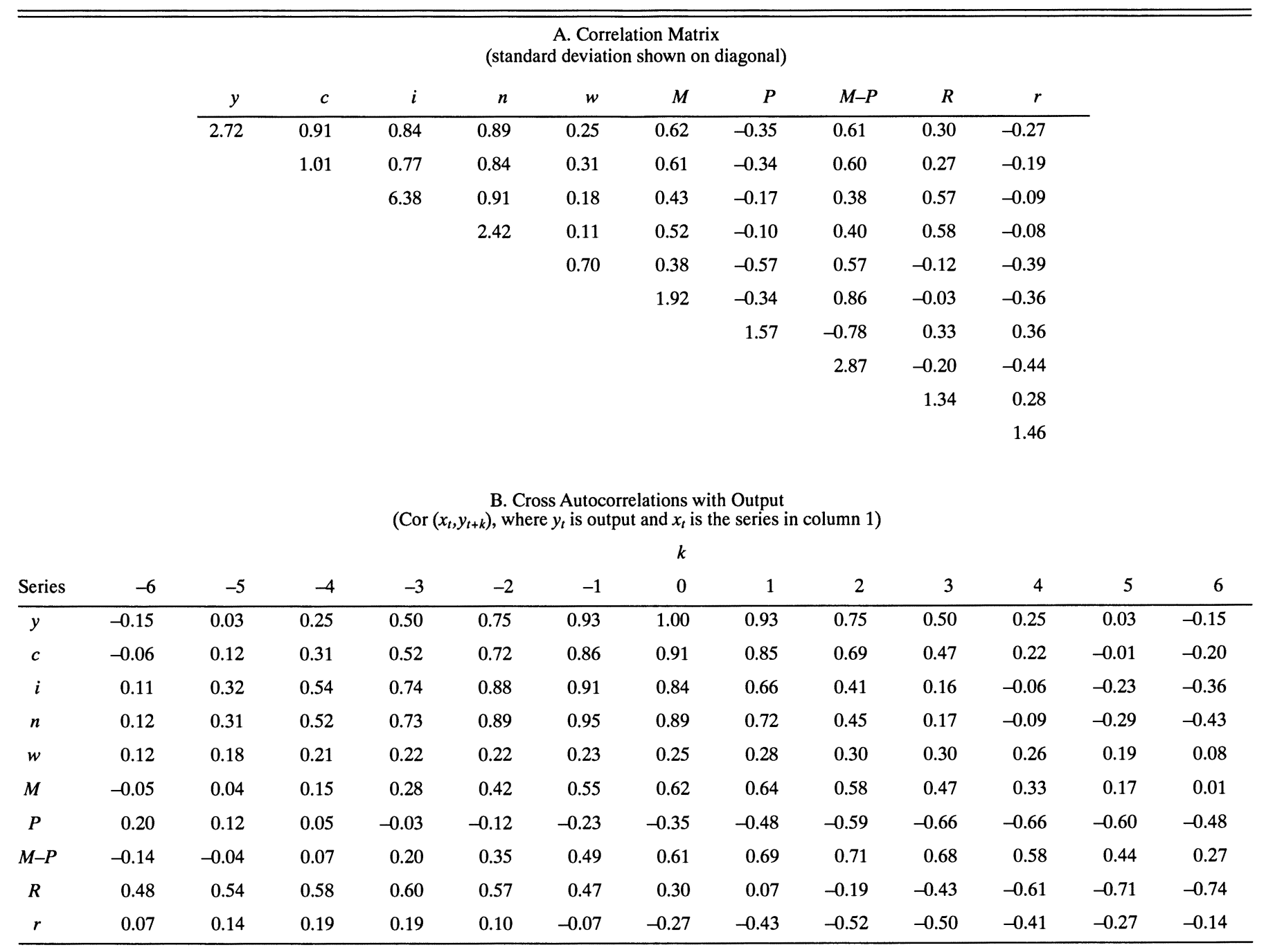

Note: These results were calculated from the estimated spectral density matrix described in footnote 13. Autocovariances were calculated from the relation $\lambda_{r}^{x y}=(1 / \pi) \int_{-\pi}^{\pi} e^{i \omega r} s^{x y}(\omega) d \omega$, where $\lambda_{r}^{x y}$ is the $r^{\text {rh }}$ cross autocovariance of $x_{t}$ and $y_{t}$, and $s^{x y}(\omega)$ is the cross-spectrum. All series (except the interest rates) are multiplied by 100, so that the standard deviations in panel A represent percentage points. Interest rates are in percentage points at an annual rate.

and real money are highly correlated with output (from panel A of table 1, the correlation is 0.62 for $M$ and 0.61 for $M-$ $P)$. The high degree of business cycle "conformability" of money and output is evident in panels $\mathrm{B}$ and $\mathrm{E}$ of figure 2 (with the late 1980s being a possible exception). Real money, and to a lesser extent nominal money, appears to lead output over the cycle. From panel B of table 1, the correlation of $M_{t}-P_{t}$ and $y_{t+2}$, is 0.71 , while the contemporaneous correlation is 0.61 .

The second important characteristic involves the relation between prices and output. The correlation between $P$ and $y$ over the cycle is -0.35 (panel A of table 1). While this suggests countercyclical movement of prices, it is evident from panel B of figure 2 that prices moved pro-cyclically in some cycles (notably the pre-1970 period) and counter-cyclically in others (notably 1970-1986). The autocorrelations from panel B of table 1 show two important features of the priceoutput relation. First, there is a tendency for prices to lead output in a countercyclical fashion. (From panel B of table $\left.1, \operatorname{cor}\left(P_{t}, y_{t+4}\right)=-0.66\right)$. Second, at long lags, prices are positively correlated with output. (From panel B of table 1, $\operatorname{cor}\left(P_{t}, y_{t-6}\right)=+0.20$ and $\operatorname{cor}\left(P_{t}, y_{t-10}\right)=+0.45$; this latter correlation is not shown in the table.) This positive correlation between prices and lagged values of output is suggestive of price stickiness in response to nominal disturbances; a model incorporating gradual price adjustment is developed in the next section to investigate this suggestion.

Finally, the third important characteristic is the systematic cyclical pattern of interest rates: nominal interest rates and output are positively correlated $\left(\operatorname{cor}\left(R_{t}, y_{t}\right)=0.30\right)$, more highly correlated when nominal rates are lagged $\left(\operatorname{cor}\left(R_{t}, y_{t-3}\right)\right.$ $=0.60$ ) and strongly negatively correlated with future output 
Figure 2. - Business CyCle CoMponents OF QUARTERLy U.S. DATA

A. Employment and Output

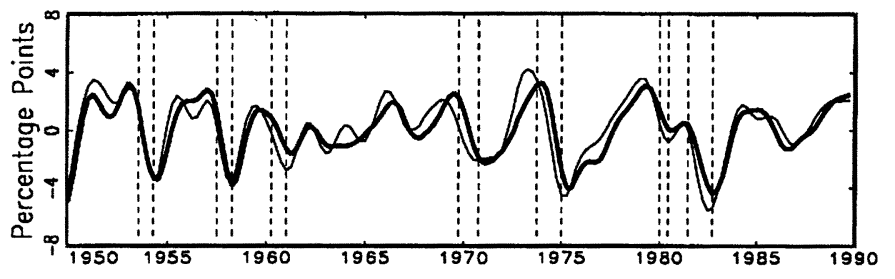

C. Prices and Output

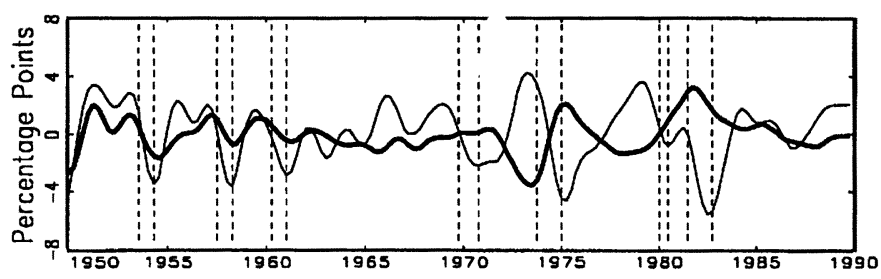

E. Real Balances and Output

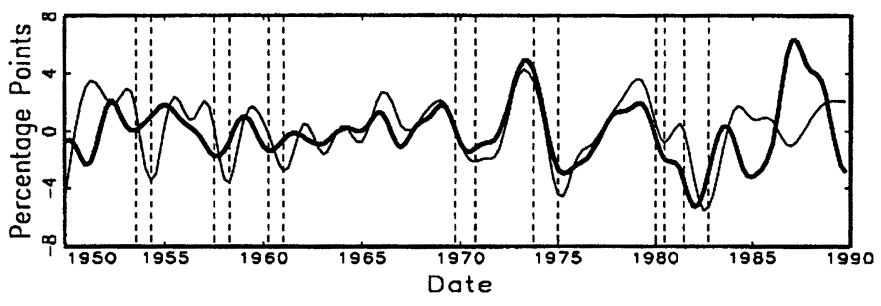

B. Money and Output

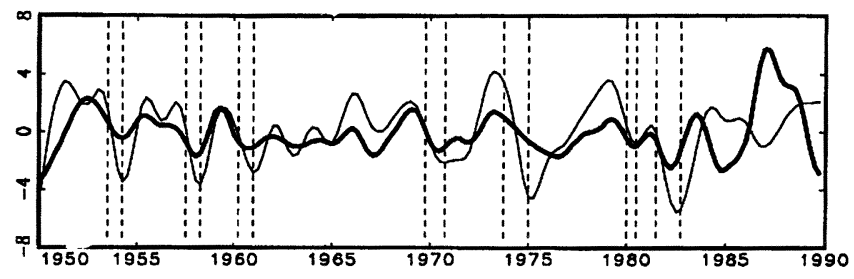

D. Nominal Interest Rates and Output

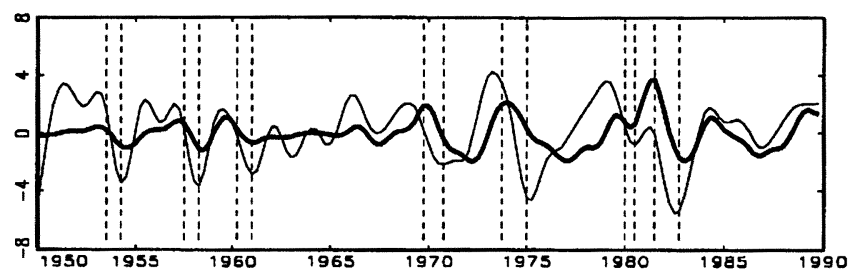

F. Real Interest Rates and Output

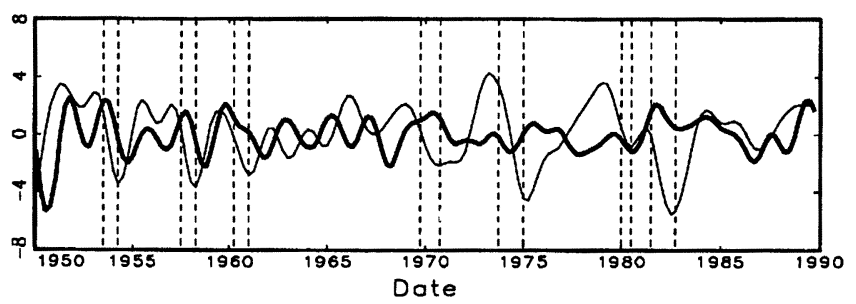

Note: Each panel shows the 6-32 quarter bandpass filtered series for output (thin line) and other series (thick line) shown in the panel heading. Vertical lines are the NBER peak and trough dates.

$\left.\operatorname{cor}\left(R_{t}, y_{t+6}\right)=-0.74\right)$. Real interest rates move countercyclically and lead output over the cycle $\left(\operatorname{cor}\left(r_{t}, y_{t}\right)=-0.27\right.$ and $\left.\operatorname{cor}\left(r_{t}, y_{t+2}\right)=-0.52\right)$. The leading countercyclical nature of real interest rates is suggestive of the types of mechanisms stressed in the models of financial market frictions that we survey in the next section.

These three characteristics of the business cycle have been documented by many empirical researchers using a variety of methods; perhaps most notably by business cycle analysts using methods that descended from the work of Burns and Mitchell (1946). (For a detailed discussion, see Zarnowitz and Boschan (1975).) For example, in the Commerce Department's system of cyclical indicators for the United States, both nominal and real money are categorized as "leading indicators" with average cyclical leads of 4 and 2 quarters, respectively. ${ }^{7}$ Real money (M2) is one of the 11 series making up the Department's monthly Index of Leading Indicators. Interest rates and general measures of price inflation are categorized as lagging indicators and both are components of the Department's Index of Lagging Indicators. ${ }^{8}$ On the other

\footnotetext{
${ }^{7}$ See Handbook of Cyclical Indicators, table 8.

${ }^{8}$ The Index of Lagging Indicators contains the average prime rate and the change in the CPI for services. Sensitive material prices are included in the Index of Leading Indicators, but this series behaves much differently than the general price level that we consider here.
}

hand, business cycle analysts and researchers working on leading indicators have long recognized the negative relation between interest rates and changes in future output (see Zarnowitz (1988)).

\section{Overview of Models}

We consider three classes of models with distinctly different mechanisms linking nominal and real variables over the business cycle: real business cycle models; models with prices that are gradually adjusting due to frictions in product markets; and models with gradual adjustment of portfolios due to frictions in financial markets. In this section, we provide an introduction to the specific versions of each type of model that we use in the remainder of our paper. A detailed description of the models is contained in King and Watson (1995a). We begin with some discussion of features that are common to all models, then discuss the details of individual setups and end with a discussion of our quantitative implementation of the models.

\section{A. Common Features}

All our models incorporate a representative household and a representative firm; we begin by discussing aspects of their behavior that are common features in the analysis below. 
The Representative Household: The representative household chooses a plan for consumption $\left(\left\{c_{t}\right\}_{t=0}^{\infty}\right)$ and leisure $\left(\left\{l_{t}\right\}_{t=0}^{\infty}\right)$ to maximize expected lifetime utility, $E_{0}\left[\sum_{t=0}^{\infty} \beta^{t} u\left(c_{t}, l_{t}\right)\right]$,where $u(c, l)$ is the momentary utility function and $\beta$ is the discount factor for future utility flows. With leisure determined (and also another use of time, $h_{t}$, incorporated in one of the models below), the representative household's labor supply $n$ is then given as a residual from the endowment of time, which is taken to be unity. Thus, $n_{t}=1-l_{t}-h_{t}$. Individuals may freely adjust their work effort so as to maximize momentary utility, so that the marginal rate of substitution of leisure for consumption equals the real wage:

$$
\frac{\partial u\left(c_{t}, l_{t}\right) / \partial l_{t}}{\partial u\left(c_{t}, l_{t}\right) / \partial c_{t}}=\frac{W_{t}}{P_{t}}=w_{t}
$$

where $W_{t}$ and $P_{t}$ are the nominal wage rate and price of consumption, respectively and $w_{t}$ is the real wage rate.

The Representative Firm: The representative firm chooses a plan for production, labor demand and investment so as to maximize the expected present value of its real profits $(\pi)$. That is, the firm maximizes $E_{0}\left[\Sigma_{t=0}^{\infty} \beta^{t} \rho_{t} \pi_{t}\right]$, where $\beta^{t} \rho_{t}$ is the discount factor applied to date $t$ real cash flows. Profits are assumed to be the value of output less the wage bill and investment.

The firm's output $y$ is related to capital input $k$ and labor input $n$ according to a production function,

$$
y_{t}=a_{t} f\left(k_{t}, n_{t}\right)
$$

where $a_{t}$ is an exogenous shifter of total factor productivity. The various models considered below will impose different restrictions on the function $f$. The capital stock evolves as

$$
k_{t+1}-k_{t}=\phi\left(i_{t} / k_{t}\right) k_{t}-\delta k_{t},
$$

where $i$ denotes investment, $\delta$ is the rate of depreciation and $\phi$ is a strictly concave adjustment cost function.

Optimal capital accumulation involves two efficiency conditions on the part of the firm. The first specifies that the marginal value of capital is equated to the marginal cost of investment: $\psi_{t} \phi^{\prime}\left(i_{t} / k_{t}\right)=\partial \pi_{t} / \partial i_{t}$, where $\psi_{t}$ is the date $t$ Lagrange multiplier that indicates the value of an additional unit of capital installation (of a small change in $k_{t+1}$ within the constraint (4)) and $\partial \pi_{t} / \partial i_{t}$ is the reduction in profits necessitated by the purchase of investment goods. The second efficiency condition is

$$
\psi_{t}=E_{t}\left[\beta \psi_{t+1} v\left(i_{t+1} / k_{t+1}\right)+\beta \rho_{t+1} \frac{\partial \pi_{t+1}}{\partial k_{t+1}}\right],
$$

where

$$
v\left(i_{t} / k_{t}\right)=(1-\delta)-\left(i_{t} / k_{t}\right) \phi^{\prime}\left(i_{t} / k_{t}\right)+\phi\left(i_{t} / k_{t}\right) .
$$

This condition stems from selecting $k_{t+1}$ optimally: it requires that the shadow value of a unit of $k_{t+1}$ (a measure of cost) is equated to the relevant expected benefit measure, which includes the effects of $k_{t+1}$ on both future capital accumulation and profits. For each model we will develop this condition in greater detail, essentially by detailing $\rho_{t+1} \partial \pi_{t+1} / \partial k_{t+1}$.

An Economy-wide Constraint: In each model there is an economy-wide constraint on the uses of output: $y_{t}=c_{t}+i_{t}$. This constraint highlights the fact the models ignore (i) fiscal interventions, including policies describing taxation and government purchases, and (ii) international trade.

\section{B. The Real Business Cycle Model}

Our analysis of the real business cycle model presumes that (i) production takes place according to a constant returns-toscale production function; and (ii) firms and households interact in frictionless, competitive markets for final product, factor inputs and finance.

Firms maximize their profits, $\pi_{t}=a_{t} f\left(k_{t}, n_{t}\right)-w_{t} n_{t}-i_{t}$, by choosing labor input such that the marginal product $a_{t} \partial f\left(k_{t}, n_{t}\right) / \partial n_{t}$ is equated to the real wage $w_{t}$. Correspondingly, the effect of capital on profit, $\partial \pi_{t} / \partial k_{t}$, is $a_{t} \partial f\left(k_{t}, n_{t}\right) / \partial k_{t}$.

Households maximize lifetime utility subject to an intertemporal budget constraint, $E_{0}\left[\sum_{t=0}^{\infty} \beta^{t} \rho_{t}\left(c_{t}+w_{t} l_{t}\right)\right]$ $\leq E_{0}\left[\Sigma_{t=0}^{\infty} \beta^{t} \rho_{t}\left(\pi_{t}+w_{t}\right)\right]$. The condition for optimal intertemporal allocation of consumption is

$$
\partial u\left(c_{t}, l_{t}\right) / \partial c_{t}=\lambda \rho_{t}
$$

where $\lambda$ is the Lagrange multiplier on the wealth constraint and $\rho_{t}$ is the real discount factor.

To consider the behavior of nominal variables, we append a money demand function of the form:

$$
\begin{aligned}
\log \left(M_{t}\right)= & \log \left(P_{t}\right)+m_{y} \log \left(y_{t}\right) \\
& +m_{R} \log \left(1+R_{t}\right)-V_{t}
\end{aligned}
$$

where $M_{t}$ is the level of the date $t$ money stock; $P_{t}$ is the date $t$ price level; $R_{t}$ is the date $t$ nominal interest rate; and $V_{t}$ is a date $t$ disturbance to the money demand function. We also incorporate the Fisherian theory of interest rate determination, written as

$$
R_{t}=r_{t}+E_{t}\left(\log \left(P_{t+1}\right)\right)-\left(\log \left(P_{t}\right)\right),
$$

where $r_{t}$ is the real interest rate.

We append a money demand function rather than deriving it from a deeper specification of transactions technology because we want our model to display an exact neutrality with respect to variations in expected inflation of a cyclical and secular form. This strong classical dichotomy makes clear the origins of various results discussed below.

\section{A Model of Commodity Market Frictions}

Recent work in Keynesian macroeconomics has stressed three major departures from the real business cycle framework described above. First, imperfect competition rational- 
izes price setting behavior by firms. Second, introduction of "overhead" components of labor and capital makes productive activity exhibit increasing returns-to-scale. ${ }^{9}$ Third, various schemes for the gradual adjustment of prices have been incorporated. ${ }^{10}$ King and Watson (1995a) provides details for our version of a Keynesian model that incorporates these features. We summarize the important characteristics of that model here.

Households: Consumers in this economy are free to choose optimal consumption and labor supply plans as in the real business cycle model (although the opportunities that they face will typically differ). We also continue to assume that there is the same money demand function specified above.

Firms, Markups and Price Adjustment: To consider pricesetting by firms, it is standard to investigate the operation of a model with imperfect competition. Notably, one can "disaggregate" the preceding real business cycle model, considering consumption as $c_{t}=\left[\int c_{t}(\omega)^{v} d \omega\right]^{(1 / v)}$, where $\omega$ is an index of an individual firm and $0<v<1$. This specification implies that demand for product $\omega$ has a constant price elasticity, $-(v-1)^{-1}$. This leads firms to set prices that are a constant markup over marginal cost $\left(M C_{t}\right)$. Denoting the gross markup $\mu$, then $\mu=1 / v$, which means that the gross markup is larger than 1 .

In its real form, the monopolistic competition macroeconomic model is closely related to the standard real business cycle model, but there are several important exceptions. First, the business cycle behavior of aggregate output is more strongly linked to fluctuations in labor and capital input: $\log \left(y_{t} / y\right) \approx \log \left(a_{t} / a\right)+\mu s_{n} \log \left(n_{t} / n\right)+\mu s_{k} \log \left(k_{t} / k\right)$, where $s_{n}$ and $s_{k}$ are the shares of labor and capital income in value-added. Second, there are implications for the elasticities of marginal product of labor,

$$
\begin{aligned}
\log \left(\frac{\partial y_{t}}{\partial n_{t}} / \frac{\partial y}{\partial t}\right) \approx & \log \left(a_{t} / a\right)-\frac{s_{k} \mu}{\zeta} \frac{n}{\tilde{n}} \frac{\tilde{k}}{k} \log \left(n_{t} / n\right) \\
& +\frac{s_{k} \mu}{\zeta} \log \left(k_{t} / k\right)
\end{aligned}
$$

\footnotetext{
${ }^{9}$ Alternative ways of introducing increasing returns-to-scale technology and consequent monopolistic competition are surveyed in Rotemberg (1987). To us, the specific setup with overhead components of labor and capital seems most natural, as it allows for profits by monopolist competitors to be paid to factor inputs. For additional details on our implementation of this setup, see King and Watson (1995a).

${ }^{10}$ See Fischer (1977), Gray (1978) and Phelps and Taylor (1977) for important early contributions. In the current paper, we explore the implications of a model of gradual price adjustment developed by Calvo (1983) and Rotemberg (1982a, 1982b). The Calvo-Rotemberg model has the attractive feature that the aggregate price level evolves as a first-order autoregression that is driven by factors which we discuss in greater detail below. Recent work by Yun (forthcoming in 1996) provides further development of the price adjustment setup of Calvo as well as providing an investigation of the empirical implications of this model.

In an earlier version of this paper and in King (forthcoming in 1996), we studied models of wage and price adjustment developed more closely along the lines of Fischer, Gray and Phelps-Taylor. Those models were essentially moving average models of wage and price adjustment.
}

and the marginal product of capital

$$
\begin{aligned}
\log \left(\frac{\partial y_{t}}{\partial n_{t}} / \frac{\partial y}{\partial t}\right) & \approx \log \left(a_{t} / a\right)+\frac{s_{n} \mu}{\zeta} \log \left(n_{t} / n\right) \\
& +\frac{s_{n} \mu}{\zeta} \frac{k}{\tilde{k}} \frac{\tilde{n}}{n} \log \left(k_{t} / k\right)
\end{aligned}
$$

which are derived in the appendices to King and Watson (1995a). In these expressions, $\zeta$ is the elasticity of substitution between capital and labor in the production function, $n / \tilde{n}$ is the ratio of total labor input to variable labor input (non-overhead labor) and $k / \tilde{k}$ is the ratio of total capital input to variable capital input (non-overhead capital). The comparable expressions for the real business cycle model involve setting $\mu=1$ and $n / \tilde{n}=k / \tilde{k}=1$. The key point is that, in general, the existence of overhead capital and labor changes the responsiveness of marginal products to changes in input quantities. When $n / \tilde{n}=k / \tilde{k}$, the elasticities of marginal products with respect to factor inputs are simply $\mu$ times their corresponding values in the real business cycle model.

To incorporate sticky prices into this model, Calvo (1983) and Rotemberg (1982a, 1982b) develop dynamic price-setting rules that are summarized by the following pair of equations:

$$
\begin{aligned}
& \log \left(P_{t}\right)-\log \left(P_{t-1}\right)=\varphi\left[\log \left(P_{t}^{*}\right)-\log \left(P_{t-1}\right)\right], \\
& \log \left(P_{t}^{*}\right)=E_{t}\left[\sum_{j=0}^{\infty}(\beta \varphi)^{j} \log \left(\mu M C_{t+j}\right)\right] .
\end{aligned}
$$

That is, the change in the price level at date $t$ depends on the gap between a "target" price level and last period's price. In turn, the target price level is a distributed lead of the fixed markup over marginal cost which would be charged in the static monopolistic competition model. Calvo rationalizes this pair of specifications with the assumption that only a fraction $\varphi$ of firms adjust their price each period and that this adjustment opportunity is allocated randomly across firms. It is consequently optimal to choose a price target that is an average of the prices that would otherwise be chosen $\left(\log \left(\mu M C_{t+j}\right)\right)$. Rotemberg (1982a, 1982b) rationalizes this specification by assuming that individual firms have quadratic costs of adjusting prices. Each author assumes that firms satisfy demand at the posted price.

Marginal cost for the firm is simply given by the cost of labor and the marginal product schedule:

$$
M C_{t}=\frac{W_{t}}{\partial y_{t} / \partial n_{t}} .
$$

The firm minimizes the cost of required production by selecting labor and capital efficiently given the exogenously specified level of demand. In the short run, with capital predetermined and output determined by demand, the firm simply must hire labor to produce output. Its "effective" demand for labor is thus implicit in the requirement that $y_{t}=a_{t} f\left(k_{t}, n_{t}\right)$, so that labor demand is positively influ- 
enced by output and negatively influenced by productivity and capital (as discussed by Barro and Grossman (1976), for example). Thus, locally, it follows that:

$$
\log \left(n_{t}\right) \approx \frac{1}{\mu s_{n}} \log \left(y_{t}\right)-\frac{1}{\mu s_{n}} \log \left(a_{t}\right)-\frac{s_{k}}{s_{n}} \log \left(k_{t}\right) .
$$

Correspondingly, the value of having an additional unit of the capital stock is the implied cost reduction from reduced labor purchases. Hence

$$
\frac{\partial \pi_{t}}{\partial k_{t}}=w_{t} \frac{\partial y_{t} / \partial k_{t}}{\partial y_{t} / \partial n_{t}}
$$

That is, if there is an additional unit of capital, it produces additional output $\partial y_{t} / \partial k_{t}$, with associated real labor cost savings of $w_{t}\left(\partial y_{t} / \partial n_{t}\right)^{-1}$.

\section{A Model of Financial Market Frictions}

Another strain of macroeconomic literature has stressed the role of financial market frictions in generating "liquidity effects" on nominal and real interest rates. In this section, we briefly present a model developed by Christiano and Eichenbaum $(1992,1993)$ that incorporates two main frictions discussed in this literature: (i) the requirement that some portfolio decisions are made without complete information about all the shocks within the period, notably prior to the actions of the monetary authority, and (ii) costs of adjusting portfolio positions.

Households: The preferences of the household are as described above, but the opportunity to trade in goods and financial markets is more restricted. Notably, consumption expenditure in the current period must be paid for with "money to spend," $S_{t}$, or current labor income, $W_{t} n_{t}$ :

$$
P_{t} c_{t} \leq S_{t}+W_{t} n_{t}
$$

The form of this constraint has two important implications. First, households can adjust labor supply so that (11) is satisfied, i.e., they are always on a "labor supply schedule" of sorts despite the financial market frictions. Second, this constraint takes the form that it does-rather than the more traditional "cash in advance" constraint of Lucas (1990), which would have the form of $P_{t} c_{t} \leq S_{t}$ in the current setupbecause firms are required to pay for labor at the start of each period. This requirement also necessitates some (costly) borrowing on the part of firms, with implications for their labor demand that are considered further below.

There are time costs of adjusting the nominal portfolio holdings, $S_{t}$, of the form $h_{t}=h\left(S_{t} / S_{t-1}\right)$, where $h\left(S_{t} / S_{t-1}\right)$ is such that marginal and average time costs are positive and marginal costs are increasing $\left(h>0, h^{\prime}>0, h^{\prime \prime}>0\right)$. Incorporation of these costs implies that the time constraint is $1-l_{t}-n_{t}-h_{t}=0$.

A key friction in the liquidity effect model is that agents must select $S_{t}$ without knowing the date $t$ values of the money stock or technology shock. After shocks occur, the cash con- straint (11) establishes a value of having an additional unit of money to spend,

$$
\begin{aligned}
\Delta_{t} & =\frac{\partial u\left(c_{t}, l_{t}\right) / \partial c_{t}}{P_{t}}-\frac{\partial u\left(c_{t}, l_{t}\right)}{\partial l_{t}} h_{t}^{\prime} \frac{1}{S_{t-1}} \\
& +\beta E\left[\frac{\partial u\left(c_{t+1}, l_{t+1}\right)}{\partial l_{t+1}} h_{t+1}^{\prime} \frac{S_{t+1}}{\left(S_{t}\right)^{2}} \mid I_{t}\right],
\end{aligned}
$$

which indicates that entering period $t$ with an additional unit of $S$ allows for the purchase of $\left(1 / P_{t}\right)$ units of consumption and also has implications for time costs of adjusting nominal portfolios (higher at $t$ and lower at $t+1$ ). This value of "money to spend" has the dimension of a utility discount factor for nominal cash flows: amounts of utility per dollar at date $t$. Thus, it is natural that under an efficient plan for $S$ that is established at the start of period $t, \Delta_{t}$ must grow faster if there is a lower nominal rate of interest:

$$
E\left[\Delta_{t}-\beta R_{t} \Delta_{t+1} \mid I_{o t}\right]=0 .
$$

Notice that in (12) and (13) we have introduced the notation $I_{o t}$ and $I_{t}$ to indicate, respectively, actions that are taken at the beginning of period $t$, i.e., without knowledge of the shocks that are impinging on the macroeconomy within $t$ and at the end of period $t$.

Firms: Firms select investment and labor demand decisions taking into account the fact that their owners face a delay in spending the profits flowing from the enterprise. Thus, firms maximize $E_{0}\left[\sum_{t=0}^{\infty} \beta^{t} \rho_{t} \pi_{t}\right]$, with $\rho_{t}=P_{t} \Delta_{t+1}$ (reflecting the delay that owners face in spending profits) and $\pi_{t}=a_{t} f\left(k_{t}, n_{t}\right)-\left(1+R_{t}\right) w_{t} n_{t}-i_{t}$ (where the labor cost term reflects the requirement that labor payments must be made in advance). The efficient labor demand decision is $a_{t}\left(\partial f\left(k_{t}, n_{t}\right) / \partial n_{t}\right)=\left(1+R_{t}\right) w_{t}$ and the efficient investment demand decision is $\psi_{t} \phi^{\prime}\left(i_{t} / k_{t}\right)=P_{t} \Delta_{t+1}$, with the evolution of the shadow price of capital following (5) with $\rho_{t+1}\left(\partial \pi_{t+1} / \partial k_{t+1}\right)=\Delta_{t+1} P_{t} a_{t}\left[\partial f\left(k_{t}, n_{t}\right) / \partial k_{t}\right]$.

Equilibrium: An additional equilibrium condition arises as a result of the joint actions of households, firms and financial intermediaries. At the start of each period, the household splits its monetary wealth into an amount that is deposited with financial intermediaries and an amount that is retained as "spending money": $M_{t-1}=Q_{t}+S_{t}$, where $Q_{t}$ is the volume of deposits. The total volume of loans that financial intermediaries can make for the purpose of financing purchases of labor by the firm is thus $W_{t} n_{t}=Q_{t}+\left(M_{t}-M_{t-1}\right)$, where the latter component is newly printed money injected via open market operations. But since (11) is satisfied as an equality in equilibrium it follows that $P_{t} c_{t}=M_{t}$.

\section{E. Quantitative Models}

Our analysis is carried out using approximate model solutions as in Kydland and Prescott (1982), King, Plosser and 
Rebelo (1988a, 1988b) and elsewhere. We begin by log-linearizing the equations that describe each of the economies around the applicable steady-state point; we then reduce the dynamic system to a state space form; and finally we solve the resulting rational expectations linear difference system using techniques like those developed in Blanchard and Kahn (1980). Details on the log-linearization of the model equations are provided in King and Watson (1995a). ${ }^{11}$

A notable feature of the three models that we are studying is that many of the steady-state attributes are not affected by the introduction of monopolistic competition or financial market frictions. In particular, as discussed in detail in King and Watson (1995a), the "great ratios" are invariant to monopolistic competition because of particular assumptions about the nature of long-run equilibrium and about the relative importance of labor and capital in the specification of fixed costs. Moreover, as also discussed in King and Watson (1995a), the key steady-state ratios of real variables are invariant to the level of sustained inflation. This similarity of steady-states in all of the models is convenient because it allows us to use a common set of parameter values estimated from long-run averages.

Parameter values for each of the models are chosen so that steady-state values match estimates of average growth rates and specific great ratios calculated from the postwar data. Specifically, using estimates constructed in King, Plosser and Rebelo (1988a), parameter values are chosen so that in steady-state each model implies $s_{n}=.58$, a per capita annual growth of $1.6 \%$, an annual depreciation rate of $10 \%$ and a real annual interest rate of $6.5 \%$. We assume that the investment adjustment cost function, $\phi$, is such that there are no average or marginal adjustment costs local to the steady-state (i.e., $\phi(i / k)=(i / k)$ and $\left.\phi^{\prime}=1\right)$. These specifications are sufficient to determine many of the great ratios of this economy, including the shares $s_{i}$ and $s_{c}$ as well as the capital-output ratio $(k / y)$.

The models also have a common determination of the long-run level of labor input. We assume that the momentary utility function takes the form: $u(c, l)=\left[c^{\theta} l^{1-\theta}\right]^{1-\sigma} /(1-\sigma)$. The marginal rate of substitution of leisure for consumption (2) together with $c / y, n / l$ and $s_{n}$ can then be used to determine the value of the preference parameter $\theta$. By contrast, the preference parameter $\sigma$, which governs the intertemporal substitutability of consumption and leisure, cannot be determined from steady-state information and we simply assume $\sigma=1$ so that utility is logarithmic. We also assume throughout that there is a unitary elasticity of substitution between capital and labor in production, i.e., that the production function takes on a Cobb-Douglas form.

\footnotetext{
${ }^{11}$ The models considered here have two complicating features. First, they are "singular," in the sense that the matrix $A$ is singular, when the models are written in standard form as $A E_{t} Y_{t+1}=B Y_{t}+C(F) E_{t} X_{t+1}$. Second, the liquidity effect model has a multistage timing structure because of the different information sets $I_{t}$ and $I_{o t}$. King and Watson (1995b) provides conditions for the solvability of singular models; a system reduction algorithm to eliminate the singularity is given in King and Watson (1995c). Techniques for solving multistage timing models are discussed in King and Watson (1995d).
}

Additional Parameters in the Real Business Cycle Model: Real business cycle models are typically built with two additional assumptions about parameters. First, there are assumed to be only small adjustment costs for investment, so that $\phi^{\prime \prime}$ is very small (or zero) and $\eta=\left[(i / k) \phi^{\prime \prime} / \phi^{\prime}\right]^{-1}$ is correspondingly very large (or infinite). (The parameter $\eta$ is the elasticity of the investment/capital ratio with respect to Tobin's q.) We accordingly adopt this assumption, setting $\phi^{\prime \prime}=0$. The parameters in the money demand process (6) are $m_{y}=1$, and $m_{R}=-0.01$. The former is essentially the long-run income elasticity estimate found in Lucas (1988) and Stock and Watson (1993). Those analyses estimated the long-run interest rate semi-elasticity to be -0.10 . We use a value that is much smaller because we think there is a smaller degree of substitution in money demand over business cycles than in the long run; at the same time, it will turn out that $m_{R}=-0.01$ is sufficiently large to generate a number of surprising results.

Additional Parameters in the Sticky-Price Model: There are three additional parameters that must be specified in this model. First, motivated by empirical studies like those of Hall (1988), we set the value of the markup of price over marginal cost $\mu$ to be 1.5 . Second, we assume that the steady-state ratios of variable to total values of labor and capital are equal, i.e., $(\tilde{n} / n)=(\tilde{k} / k)$. Under the assumption that entry eliminates any steady-state profits, it follows that,$\tilde{n} / n)=(\tilde{k} / k)=\mu^{-1}$. Third, we specify a price adjustment parameter of $\varphi=0.10$ in equation (7); this implies that $10 \%$ of the pricing discrepancies are eliminated per quarter. Finally, we set the investment cost parameter $\eta=1$ in line with Chirinko's (1993) overview of empirical investment functions. While not strictly required for the study of commodity market frictions, the substantial investment adjustment costs implied by this elasticity are consistent with much conventional macroeconometric work.

Additional Parameters in the Financial Market Frictions Model: To develop the quantitative version of the financial market frictions model, we need to specify the time costs of adjusting portfolios. As in Christiano and Eichenbaum (1993), the natural procedure is to specify that there are small average and marginal time costs near the steady-state position. We assume that in steady state, individuals spend $1 \%$ of their working time in portfolio rearrangement, so that $\underline{h}=$ $0.01 * \underline{n}=0.002$ and that the initial steady-state position involves an annual inflation rate of $4 \%$. Then, we assume that a rise in the inflation rate by $4 \%$ would increase $h$ to (1.06) $\underline{h}$, and a similar decline would move $h$ to $(.95) \underline{h}$. These assumptions are sufficient to determine the derivatives of portfolio adjustment cost function: $h^{\prime}=5.5 \underline{h}$ and $h^{\prime \prime}=100 \underline{h}$.

\section{Empirical Evaluation of the Models}

In this section, we evaluate how well the three macroeconomic models capture two sets of stylized facts about postwar U.S. business cycles: (i) the patterns of business cycle variability, as revealed by the spectra of growth rates and the standard deviations of business cycle components of eco- 
FigURE 3. - SPECTRA OF DRIVING PROCESSES

\begin{abstract}
A. Productivity Growth
\end{abstract}

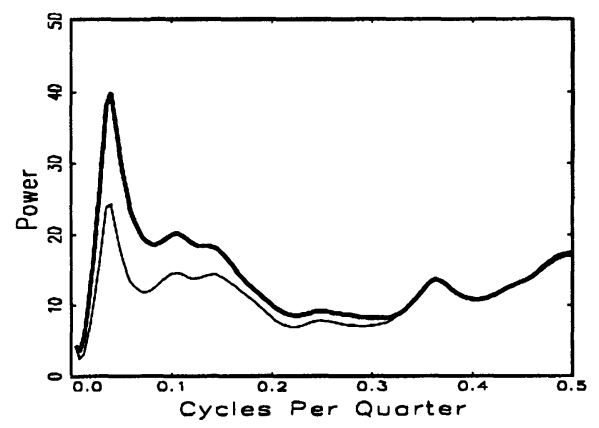

B. Money Supply Growth

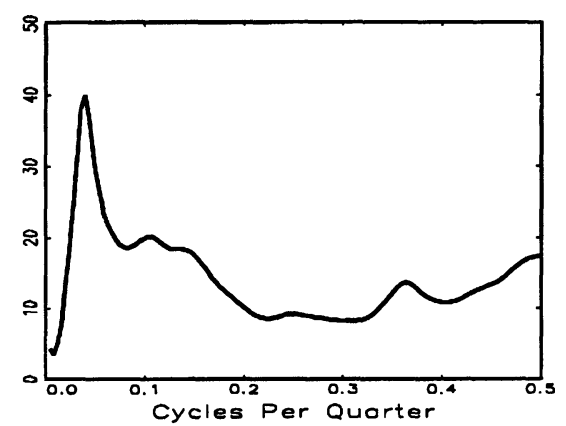

c. Money Demand Shifts

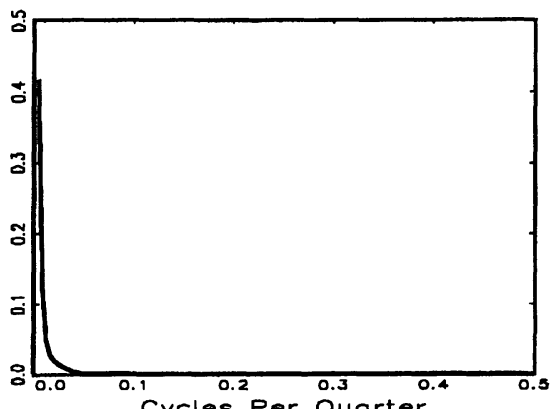

Note: The thick lines show the spectra for the real business cycle model (panels A-C), the sticky-price model (panels B-C), and the financial market friction model (panels A-B). The thin line denotes the spectrum for the growth rate of productivity in the sticky-price model.

nomic activity; and (ii) the comovements of real and nominal variables. Throughout the remainder of the paper, we will make comparisons between model outcomes and actual postwar values of the logarithms of output, consumption, investment, employment, real wages and the levels of nominal and real interest rates. Thus, for example, we will interpret $y$ as the logarithm of output in a model economy and we will let $y^{d}$ denote the logarithm of actual output.

\section{A. Specification of Realistic Driving Processes}

Two goals underlie the specification of the driving processes. First and most obviously, we want the autocovariance properties of the model's driving process to mimic those of the data. Second, we want the driving processes to be general enough, so that, at least in principle, the autocovariances of the models' variables can match those of the data. This latter requirement means that the driving processes must be specified in terms of a large number of underlying shocks. ${ }^{12}$

\begin{abstract}
12 Technically, we want to produce models for which there is a nonsingular spectral density matrix, as will be found in the data. To discuss this requirement, consider the real business cycle model driven solely by a scalar autoregressive process for technology shocks and restrict attention to the implications for real variables. Due to the dynamic nature of this model, any two real variables will not be perfectly correlated, as they may respond differently through time: consumption will, for example, be smoother than output.

However, the correlation in the frequency domain-as revealed by the spectral density matrix - will be unity for these variables, since each is a distributed lag of a single innovation. Our procedure introduces a driving process with as many innovations as variables and overcomes this singularity.

Models with multiple shocks can't eliminate singularities when the endogenous variables are functions only of current and lagged values of the driving variables. However, in models with forward looking expectations and multiple driving shocks the endogenous variables will, in general, depend on all of the shocks in the system.
\end{abstract}

Figure 4. - SPECTRA OF DATA AND MOdELS

A. Output Growth

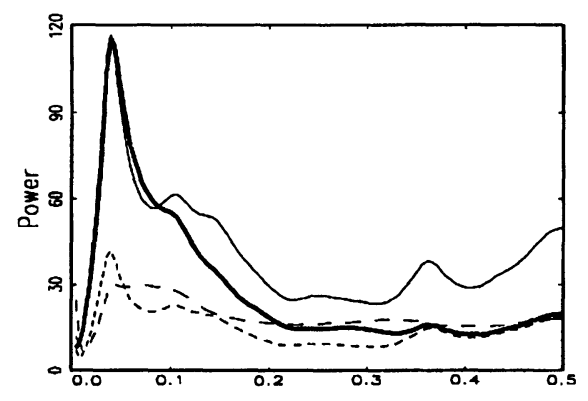

D. Growth in Real Bolances

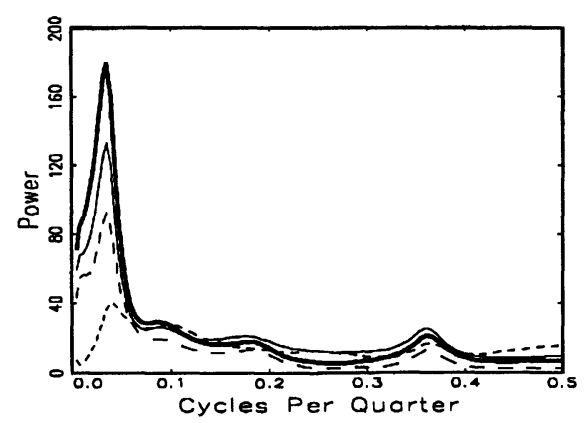

B. Employment Growth

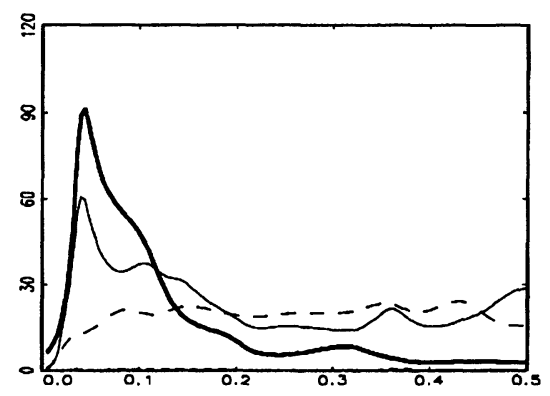

E. Nominal Interest Rates

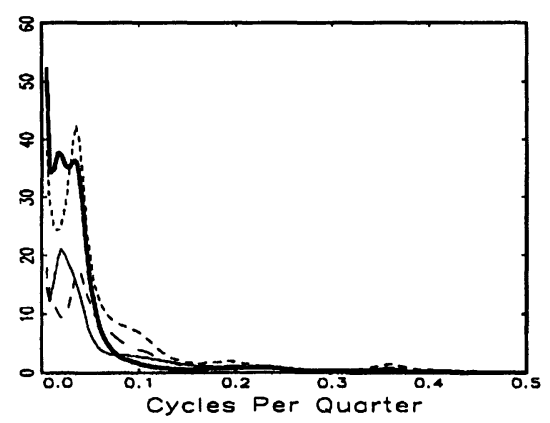

C. Price Inflation

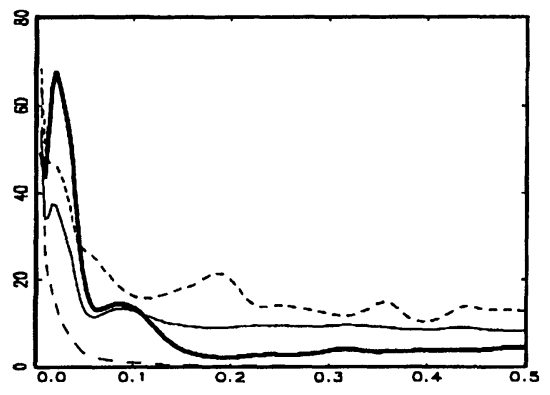

F. Real Interest Rates

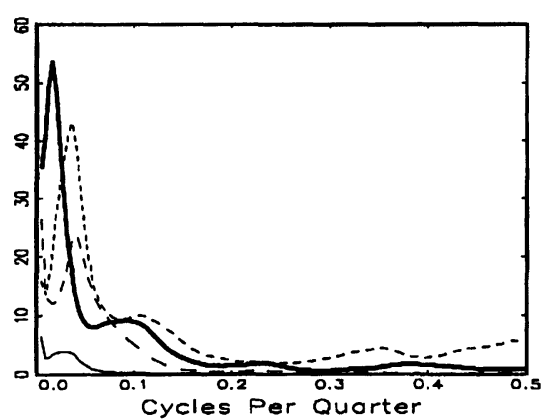

Note: Each panel shows the spectra of postwar quarterly U.S. data (thick line), the real business cycle model (thin line), the sticky-price model (long dashes), and the financial market frictions model (short dashes). 
TABLE 2. - CORRELATION MATriX OF Business-CyCle CoMPONENTS OF VARIABLE (STANDARD DEVIATION SHOWN ON DIAGONAL)

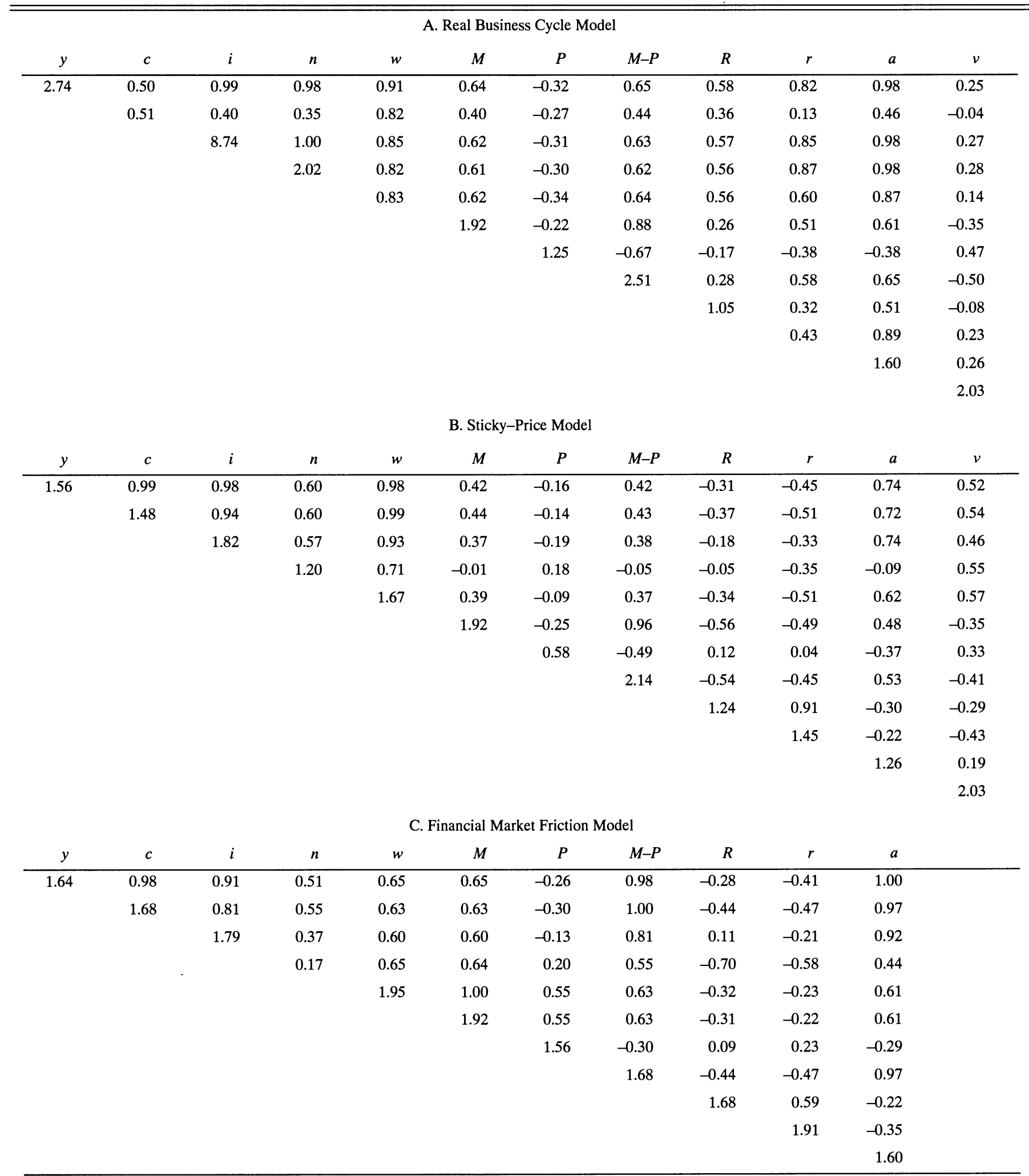

Note: These results were calculated from the spectral density matrix of the models using parameter values discussed in the text. See notes to table 1 for additional details. 
TABLE 3. - SUMMARY OF CROSS-CORRELATIONS

\begin{tabular}{|c|c|c|c|c|c|c|c|c|c|c|c|c|c|c|}
\hline \multirow{2}{*}{ Data } & \multirow{2}{*}{$\begin{array}{r}\sigma_{y, b c} \\
2.72\end{array}$} & \multicolumn{13}{|c|}{ Correlations of $y_{t+k}$ with } \\
\hline & & $\begin{array}{r}y_{t} \\
\pm 4 \\
\end{array}$ & -4 & 0 & 4 & -4 & 0 & 4 & -4 & 0 & 4 & -4 & 0 & 4 \\
\hline \multicolumn{15}{|l|}{ A. Baseline Models } \\
\hline SP & 1.56 & 0.10 & 0.38 & 0.42 & -0.21 & 0.18 & -0.16 & -0.40 & -0.53 & -0.45 & 0.46 & -0.57 & -0.31 & 0.39 \\
\hline LE & 1.64 & 0.23 & 0.31 & 0.65 & 0.13 & 0.07 & -0.26 & 0.02 & -0.51 & -0.41 & 0.50 & -0.39 & -0.28 & 0.48 \\
\hline \multicolumn{15}{|l|}{ B. Other Models } \\
\hline $\mathrm{RBC}-\mathrm{I}$ & 2.74 & 0.23 & 0.00 & 0.00 & 0.00 & 0.04 & -0.45 & -0.32 & -0.23 & 0.82 & 0.61 & 0.34 & 0.64 & -0.12 \\
\hline SP-I & 1.98 & 0.13 & 0.50 & 0.42 & -0.20 & 0.60 & 0.30 & -0.41 & -0.41 & -0.34 & 0.36 & -0.40 & 0.23 & 0.43 \\
\hline $\mathrm{SP}, \eta^{-1}=0$ & 3.11 & 0.02 & 0.22 & 0.52 & 0.04 & 0.25 & -0.07 & -0.55 & -0.34 & 0.89 & 0.22 & -0.22 & 0.85 & 0.04 \\
\hline SP-M & 1.31 & 0.24 & 0.76 & 0.64 & -0.30 & 0.78 & 0.55 & -0.34 & -0.59 & -0.13 & 0.46 & -0.51 & 0.38 & 0.56 \\
\hline $\mathrm{SP}, m_{R}=0$ & 2.39 & 0.05 & -0.00 & 0.51 & 0.28 & 0.56 & 0.17 & -0.71 & -0.59 & -0.20 & 0.56 & -0.57 & 0.00 & 0.56 \\
\hline $\mathrm{SP}-\mathrm{M}, m_{R}=0$ & 1.31 & 0.27 & 0.44 & 0.97 & 0.19 & 0.65 & 0.73 & 0.01 & -0.57 & -0.11 & 0.65 & -0.57 & 0.05 & 0.72 \\
\hline $\mathrm{SP}, m_{R}=-.10$ & 1.44 & 0.10 & 0.32 & -0.21 & -0.39 & 0.03 & 0.30 & 0.13 & -0.43 & -0.64 & 0.23 & -0.53 & -0.53 & 0.21 \\
\hline LE-I & 1.58 & 0.24 & -0.00 & 0.06 & 0.03 & -0.16 & -0.60 & -0.12 & -0.53 & -0.31 & 0.53 & -0.03 & -0.06 & 0.02 \\
\hline LE-M & 0.12 & 0.18 & -0.02 & 0.76 & 0.45 & -0.11 & 0.67 & 0.52 & 0.32 & -0.42 & -0.08 & -0.42 & -0.71 & 0.22 \\
\hline
\end{tabular}

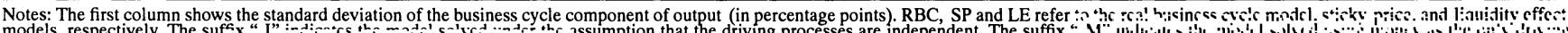

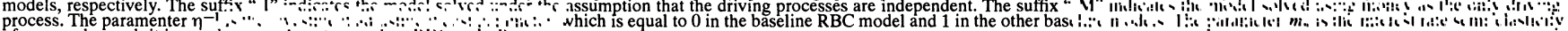

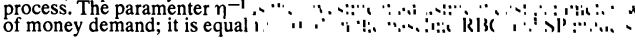

To achieve these goals, we specify a driving process constructed from an eight variable VAR estimated from post-war U.S. data. Specifically, let $y_{t}^{d}, c_{t}^{d}, i_{t}^{d}, n_{t}^{d}, w_{t}^{d}, M_{t}^{d}, P_{t}^{d}$ and $R_{t}^{d}$ denote the postwar values of the logarithms of output, consumption, etc., that were described in detail in section II above. (The superscript $d$ is used as reminder that these are data and may differ from their counterparts generated by the models.) Let $\delta_{t}=\rho \delta_{t-1}+h \xi_{t}$ denote the companion form of the VAR representing these data and let $x_{t}$ denote the exogenous driving variables in one of the models (e.g., $x_{t}=\left(a_{t}\right.$, $\left.M_{t}, V_{t}\right)$ in the RBC model). The process for $x_{t}$ is specified as

$$
\begin{aligned}
& x_{t}=Q \delta_{t} \\
& \delta_{t}=\rho \delta_{t-1}+h \xi_{t} .
\end{aligned}
$$

In (15), the vector $\xi_{t}$ has the same characteristics as the VAR residuals estimated from the data: $\xi_{t}$ is an $8 \times 1$, zero mean, white noise vector. Thus, in the RBC model the three driving variables depend on eight shocks. If only three shocks were used, then any subset of four or more variables in the models would be dynamically singular. This is avoided by allowing $\xi_{t}$ to include eight distinct shocks.

The matrix $Q$ in (14) is model-specific and is chosen so that the driving variables in the models have autocovariances that match their empirical counterparts in the data. In the RBC model, $Q$ is chosen so that the autocovariances of $\Delta a_{t}$, $\Delta M_{t}$, and $V_{t}$ match those of $\Delta a_{t}^{d}=\Delta y_{t}^{d}-\theta_{n} \Delta n_{t}^{d}, M_{t}^{d}$ and $V_{t}^{d}=-M_{t}^{d}+P_{t}^{d}+m_{y} y_{t}^{d}+m_{R} R_{t}^{d}$ (in these expressions $\theta_{n}=0.58$, estimated as labor's average share of national income, $m_{y}=1$ and $\left.m_{R}=-0.01\right)$. The variables $\left(\Delta a_{t}^{d}, M_{t}^{d}\right.$, $\left.V_{t}^{d}\right)$ are the data's natural analogues of the model's exogenous variables $\left(\Delta a_{t}, \Delta M_{t}, V_{t}\right)$, except that $\Delta a_{t}^{d}$ excludes the term $-\theta_{k} \Delta k_{t}^{d}$ on the grounds that this term has a very small variance and is poorly measured in the data. In the sticky-price model, the definition of $x_{t}$ is the same, except that $\theta_{n}=0.87$, which is labor's average share multiplied by a markup parameter of 1.5. Mechanically, this leads to a less volatile series for productivity shocks, with implications that we trace out below. In the financial market frictions model, 
the variables are the same as the RBC model, except that $V_{t}$ is excluded from $x_{t} \cdot{ }^{13}$

The spectra of these driving processes is shown in figure 3 . The first two panels show the spectra of annual growth rates of productivity and money $\left(400 \Delta a_{t}\right.$ and $400 \Delta M_{t}$, respectively); the last panel shows the spectrum of the level of $V_{t}$. The growth rates of both productivity and money are positively serially correlated with significant mass at the business cycle frequencies. The productivity process in the stickyprice model is less variable than in the other models because of the larger labor elasticity in the production function. The process for velocity, while stationary, is highly persistent, with a spectral shape similar to nominal interest rates (see figure 1, panel E).

\section{B. Results for the Three Macro Models}

The second moment properties of the macroeconomic models are summarized in figure 4 and tables 2 and 3 . The figures and tables highlight different aspects of the operation of these models.

Figure 4 shows the spectra of the growth rates of macroeconomic variables in the models along with the estimated spectra of the growth rates of the counterpart variable in the postwar U.S. data. It displays the extent to which the models capture the variability of the growth rates of output, employment, money, etc., at different frequencies; we focus our discussion on the business cycle frequencies, i.e., periodicities between 6 and 32 quarters.

Tables 2 and 3 present the information on the levels of the economic variables, once these have been passed through the business cycle filter that eliminates trend and irregular components, as described in section II. Table 2 shows the correlation matrix of the business cycle filtered versions of the variables; table 3 shows selected cross-correlations of the filtered series with the filtered values of output (contemporaneously and at a one year lead and lag). We view these correlations as describing the comovement of individual series with the business cycle, since we take output as our reference measure of the business cycle.

Before describing the results for the specific models, we highlight five low-frequency features of the model spectra. First, since each of these models exhibits long-run balanced

\footnotetext{
${ }^{13}$ The estimated VAR underlying (15) was specified using $\Delta n_{t}^{d}, \Delta w_{t}^{d}, M_{t}^{d}$, $R_{t}^{d}, y_{t}^{d}-c_{t}^{d}, y_{t}^{d}-i_{t}^{d},\left(M_{t}^{d}-P_{t}^{d}-y_{t}^{d}\right)$ and $\left(w_{t}^{d}-y_{t}^{d}+n_{t}^{d}\right)$. This mixture of levels and differences uses integration characteristics of the data familiar from a large body of empirical research. In particular, the specification imposes three unit roots or stochastic trends in the system. These trends are shared by the variables in a way that is consistent with (i) balanced growth in $y, c$ and $i$, (ii) stable long-run money demand with unit income elasticity (see Lucas (1988) and Stock and Watson (1993)), and (iii) balanced real wage and labor productivity growth. Of course, during estimation, the VAR is free to ignore these relations by differencing the level variables. That is, while this specification imposes a minimum of three unit roots, it also accommodates higher order integration. Thus, for example, it nests specifications with integrated interest rates, money growth, price inflation, and money demand. In addition to forming the basis for (15), the estimated VAR was also used to calculate estimated spectra of the data shown in figure 1. The VAR included a constant term and was estimated over the period 1949:1-1992:4. (Data before 1949:1 were used to initialize the VAR.) The estimated data spectra were computed using a VAR with six lags.
}

growth, the heights of the spectra at frequency zero for $\Delta y, \Delta c$ and $\Delta i$ are equal. Second, since long-run growth arises from movements in productivity, the low frequency behavior of $\Delta y$, $\Delta c$ and $\Delta i$ is closely related to the low frequency behavior of the driving process for $\Delta a_{t}$. (In particular, the long-run effect of a permanent technology shock on output is $1 / \alpha$, where $\alpha$ is the elasticity of output with respect to labor input; hence the height of the spectrum for output is about 3 times that of technology when $\alpha=.6$ ). Third, per-capita employee hours, $n_{t}$, is stationary in each of the models and hence has no spectral mass at frequency zero. Fourth, the velocity of money $(y-$ $M+P)$ is stationary in each of the models, so that long-run movements in real balances match those of $y$, which in turn implies that the spectra of $\Delta(M-P)$ and $\Delta y$ coincide over low frequencies. Finally, stationary velocity together with the long-run neutrality of money in each of the models, implies that at frequency zero, the spectrum of $\Delta P$ is equal to the sum of the spectrum of $\Delta M$ and the spectrum of $\Delta y$. We will now discuss each of the models in turn.

1. The RBC Cycle Model with Endogenous Money: The RBC model-using the standard parameterization employed here and the driving processes described above- produces output, consumption and investment that behave much like the data in terms of their spectra. (Figure 4 shows the spectrum for output. The shapes of the spectra for consumption and investment (not shown) are similar, although with heights reflecting their relative variances, see King and Watson (1995a, figure 5.2).) This finding is strikingly different from that of Watson (1993) and is traceable to a simple difference from the assumptions of that paper: here the driving process for technology displays substantial mean reversion, rather than the random walk considered in Watson (1993). In the RBC model, the implied dynamics of output variables closely match the assumed process for productivity and thus the shape of the spectra for these models reflects the assumed spectra of the input process for $a_{t}$. This strong linkage between assumptions about driving processes and model outcomes has been previously noted by other authors, e.g., Rotemberg and Woodford (1994).

The spectrum for $\Delta y$ is quite similar to the spectrum estimated from the data (see panel A of figure 4); this similarity carries over to the spectra of $\Delta c$ and $\Delta i$ (not shown). ${ }^{14}$ The only notable difference between the model and data for $y, c$ and $i$ is that consumption is less and investment is more volatile in the model than in the data, as can be seen be comparing tables 1 and 2. This outcome reflects the fact that the "permanent income" determination of consumption implies substantial smoothing in the face of mean reversion in productivity. ${ }^{15}$ Interestingly, panel B of figure 4 shows that employment is

\footnotetext{
${ }^{14} \mathrm{We}$ present a more complete set of spectra and additional information on other moments in King and Watson (1995a). When we make reference to graphs, etc., that are not shown in this text, the interested reader will find the material there.

${ }^{15}$ However, this "defect" could be remedied easily by allowing small adjustment costs in investment. The relative variability of investment and consumption are quite close to the data when the model is solved with $\eta^{-1}=.05$.
} 
somewhat less volatile in the model than in the data, but markedly less so than in Watson's (1993) study. (From panel A of table 2, the cyclical standard deviation of employment is $2.02 \%$ in the model; from panel A of table 1, the standard deviation of the data is $2.42 \%$.) Again this result is traceable to a key feature of the real business cycle model: there is substantial intertemporal substitution in labor input when there is substantial mean reversion in productivity. Overall, this neoclassical model of consumption, investment and income determination works well, at least in terms of the characteristics shown here. However, the RBC model seriously underpredicts the variance of the real interest rate: the standard deviation for the real rate in the model is 0.43 - the corresponding value for the data is 1.46 .

The RBC model also has volatility implications for nominal variables and some of these are far from the data's empirical estimates. Panel $\mathrm{C}$ shows that the real business cycle model displays too little price volatility, although there is a peak in the spectrum at the business cycle frequencies. (In terms of the standard deviations in tables 1 and 2, the standard deviation of the business cycle component of the price level is $1.57 \%$ in the data, but it is only $1.25 \%$ in the model.) Further, panel D shows that the spectrum of real balances in the RBC model is close to estimates from the data and shares the "typical spectral shape" of the growth rates of other real variables. Finally, the real business cycle model implies too little volatility in the nominal interest rate (as indicated by panel $\mathrm{E}$ of figure 4).

The cyclical covariability of key real and nominal variables is summarized in table 3 . This table shows the cyclical cross correlation between output and money, prices and nominal and real interest rates both contemporaneously and at a lead and lag of 4 quarters. Panel A of the table summarizes the results for the data and then for our baseline parameterization of the RBC, sticky-price and financial market friction models. Panel B shows results for various modifications of the baseline models that we have produced to help understand how the results depend on our assumptions about driving processes and model parameters. ${ }^{16}$

We will use table 3 repeatedly in the following manner. First, we compare the first row of the table (the data) with results from each of the models. Thus comparing the first and second rows of the table shows that the RBC model closely captures the cyclical behavior of money evident in the data. Of course, since money is neutral in this model, all of the covariability between money and output arises from the assumed correlation of the input processes for $a_{t}$ and $M_{t}$. Here, the close match between the data and model arises from two related features. First, as we stressed above, $y_{t}$ is highly correlated with $a_{t}$ in the RBC model. Second, $y_{t}^{d}$ is highly correlated with $a_{t}^{d}$ in the data. Thus, since the model's correlation between $a_{t}$ and $M_{t}$ matches the data, the same is expected for $y_{t}$ and $M_{t}$. The cross correlations for the other

${ }^{16}$ More detailed results are presented in King and Watson (1995a, appendix D) for all of the models in table 3 . variables are less prone to match those in the data by construction. Money is also a leading indicator for output, $\operatorname{cor}\left(M_{t}, y_{t+4}\right)=0.18$, but somewhat less so than in the data, where $\operatorname{cor}\left(M_{t}, y_{t+4}\right)=0.33$. The correlation of money and output arises solely from the correlation of $a_{t}$ and $M_{t}$ : to show this, the first row of panel B shows the results from solving the model with independent driving processes. That is, in the model, each of the driving processes has the same autocovariances/spectrum as in the benchmark model, but all cross-autocovariance/cross spectra are set to zero. Under this assumption, money and output are uncorrelated.

The price level in the model is countercyclical $\left(\operatorname{cor}\left(P_{t}, y_{t}\right)=\right.$ -0.35 in the data and $\operatorname{cor}\left(P_{t}, y_{t}\right)=-0.32$ in the model). The RBC model also predicts that prices should be an inverted leading indicator for output $\left(\operatorname{cor}\left(P_{t}, y_{t+4}\right)=-0.46\right)$ but not as strongly as in the data $\left(\operatorname{cor}\left(P_{t}, y_{t+4}\right)=-0.66\right)$. Interestingly, the countercyclical nature of prices occurs in this model in spite of the strong positive feedback from output to money (more precisely, from $a_{t}$ to $M_{t}$ ). Indeed, when the model is solved using the same univariate processes for the driving variables, but assuming no feedback (the first row of panel B of table 3 ), the correlation between prices and output is more negative: monetary changes are partly accommodating productivity changes in the model, so that the price level is less strongly countercyclical.

Nominal interest rates in the model show much the same cyclical lead-lag relation as the data, albeit with smaller correlations. However, this isn't true of the real rate of interest. In the data, the real interest rate is negatively correlated with contemporaneous values of output and even more highly negatively correlated with output four quarters hence. In the model, $r_{t}$ is highly positively correlated with $y_{t}$ and $y_{t+4}$. This result occurs in the model because output is driven by persistent changes in productivity. Positive productivity disturbances lead to expected growth in consumption, associated increases in real interest rates and higher current and future output. As shown in row 2 of panel B of the table, this procyclicality of real rates depends on the assumed investment adjustment cost parameter: with large investment adjustment costs, real rates become negatively correlated with output. ${ }^{17}$ However, this large value of the adjustment cost parameter also eliminates the cyclical variability of labor input in the real business cycle model: large investment adjustment costs make it less desirable for agents to intertemporally substitute labor input.

2. The Sticky-price Model: There are several noteworthy aspects of the sticky-price model in terms of its implications for business cycle variability. To begin, from panel $\mathrm{A}$ of figure 4 and panel C of table 2, output in the model is less variable than in the data or in the RBC model. There are two reasons for this. First, the fitted process for $a_{t}$ is less variable in the sticky-price model (see panel A of figure 3 ) than in the RBC

\footnotetext{
${ }^{17}$ By large investment adjustment costs, we mean that we use the same parameter values that are employed in the sticky-price model. This involves changing $\eta^{-1}$ from 0 to 1
} 
model. Second, the assumed level of investment adjustment costs is higher in this model than in the RBC model $\left(\eta^{-1}=1\right.$ in the sticky-price model and $\eta^{-1}=0$ in the $\mathrm{RBC}$ model). In line 5 of panel $\mathrm{B}$ of table 3 , results are reported for the sticky-price model under the zero investment adjustment costs assumption: it produces more volatility in output than is present in the data.

The fact that there are high investment adjustment costs in the sticky-price model has implications for the variability of investment and consumption: from panel B of table 2, consumption is much more variable and investment much less variable than in the data. This result also arises in the RBC model when $\eta=1$. However, in the RBC model with high investment adjustment costs, employment variability is very low; yet in the sticky-price model, it remains high (see panel B of figure 4). Roughly, this occurs because in the stickyprice model employment must accommodate any short-run changes in aggregate demand and must move inversely with productivity shocks so that a given demand-determined level of output is produced.

The price level in this model is very smooth (table 2 shows that the standard deviation in the model is 0.58 and it is 1.57 in the data). In terms of the power spectrum, the model does not have a hump at the business cycle frequencies: there is simply great power at very low frequencies. Potentially, these two features may indicate that there is "too much price stickiness" present in this economy, but we have not experimented with the sensitivity of the shape of the spectra to the chosen value of the price adjustment parameter.

Finally, the sticky-price model predicts much more volatility in real interest rates than does the RBC model and, in fact, virtually exactly matches the amount that is present in the data (the standard deviation of the real interest rate in table 2 is 1.45 and it is 1.46 in the data). This is due to a combination of two features: the effects of nominal shocks on the real rate and the presence of investment adjustment costs. We will return later to discussing some aspects of the effect of investment adjustment costs.

Turning to the cyclical covariance properties of the model, several additional and surprising results stand out. First, there is important contemporaneous correlation between money and output, although not as much as is present in the data (cor $\left(M_{t}, y_{t}\right)=0.42$ in the model and $\operatorname{cor}\left(M_{t}, y_{t+4}\right)=0.62$ in the data). However, money is negatively related to future values of output. This result is not due to feedback in the driving process; it continues to be obtained when independent driving processes are used (row 4 of panel B) or when the model is solved using money as the only driving process (row 5). Instead, this negative correlation arises from two aspects of the model: (i) mean reversion in the money process; and (ii) the positive relation of nominal interest rates and aggregate demand associated with interest elastic money demand. To see why these aspects of the model are important, note that when $M_{t}$ is high, then mean reversion implies that it is expected to decline. This, together with sticky prices, leads to declines in expected future prices, interest rates and output.
When $m_{R}=0$ so that money demand is not interest elastic, the link between nominal interest rates and aggregate demand is broken and the negative correlation between $M_{t}$ and $y_{t+4}$ disappears (rows 7 and 8).

The cyclical behavior of price level in this model also differs from what one might expect. The price level is negatively correlated with current output, and it is even more strongly negatively correlated with future output (the magnitude of these correlations is somewhat smaller than those in the data). Finally, there is a small positive correlation with lagged output, rather than the large one that one might guess would describe a model with sticky prices. These surprising results are traceable to two features of the model that we constructed. First, if we make money independent of productivity or if we make it the only driving process, then a positive correlation emerges (see line 4 of panel B of table 2 for the independent process assumption and lines 6 and 8 for money as the only shock). ${ }^{18}$ These modifications also typically introduce a very large, positive correlation between lagged output and the price level. Second, the forward-looking nature of money demand plays a crucial role in governing whether the model predicts that the price level will be an inverted leading indicator. If we assume that $m_{R}=$ 0 and allow only money shocks in the model, as in line 8 of panel B of table 2 , then there is no correlation.

The nominal interest rate in this sticky-price model is a positive leading indicator of output and a negative lagging indicator; in the data the opposite occurs. Further, in the entire battery of modifications of the sticky-price model that we study in panel B of table 3, there is no modification that makes the nominal interest rate an inverted leading indicator.

The real interest rate in this sticky-price model is negatively related to output. This reflects a feature of the stickyprice model discussed above: investment adjustment costs induce diminished ability to substitute over time. Indeed, with high adjustment costs, even the RBC model implies that the real interest rate should be negatively correlated with output (see line 2 of panel B of table 3 ). However, it is again the case that neither the basic sticky-price model (or any of the modifications that we study) makes the real interest rate an inverted leading indicator for output. In the data, we find that $\operatorname{cor}\left(r_{t}\right.$, $\left.y_{t+4}\right)=-0.41$ and we find that cor $\left(r_{t}, y_{t+4}\right)=0.46$ in the basic sticky-price model.

3. The Liquidity Effect Model: The baseline results for the financial frictions model are most notable for what they don't say about the relation between financial market frictions and the business cycle. That is, when looking at the real variables

\footnotetext{
${ }^{18}$ These experiments thus shed light on one sticky-price model's answer to a conjecture of Ball and Mankiw (1994). These authors argued that high-pass filtering (of the specific sort undertaken with the Hodrick-Prescott filter) gives rise to a tendency for output and the price level to be negatively related in sticky-price models that are driven entirely by demand shocks. The band-pass filters that we employ might well be subject to the same criticism, since these are closely related to the HP filter. However, the price level is positively related to output in all of the "money shock only" models that we study in panel B of table 3. For our models, the correct interpretation of the negative correlation is that productivity shocks are indeed a major source of business cycles.
} 
A. Output

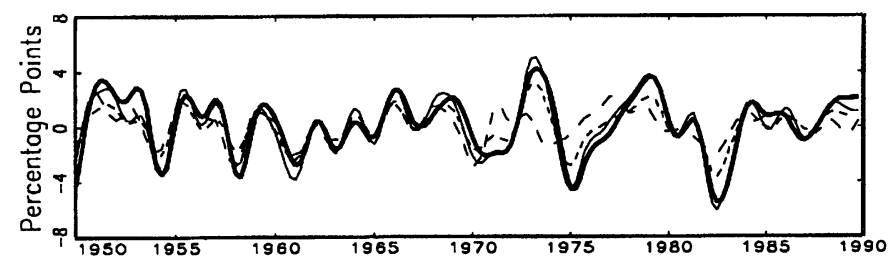

C. Prices

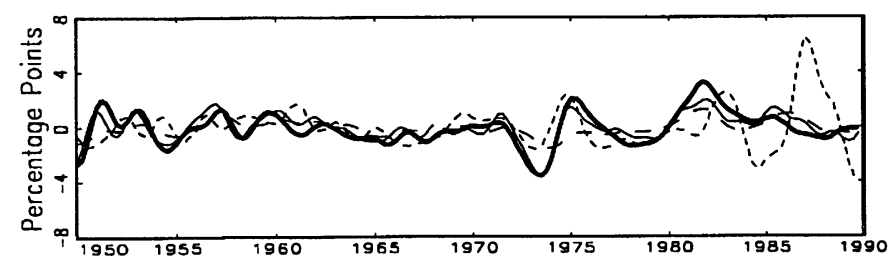

E. Nominal Interest Rates

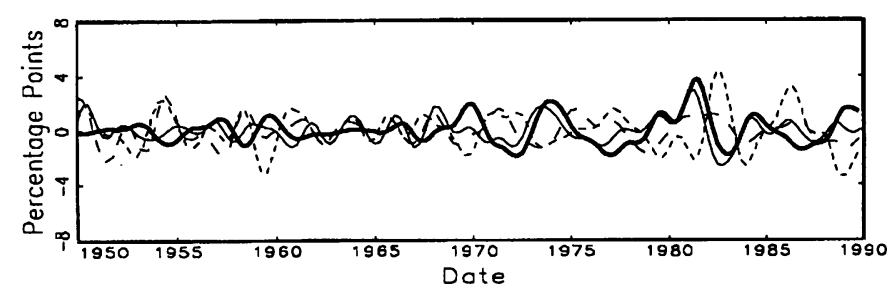

B. Employment

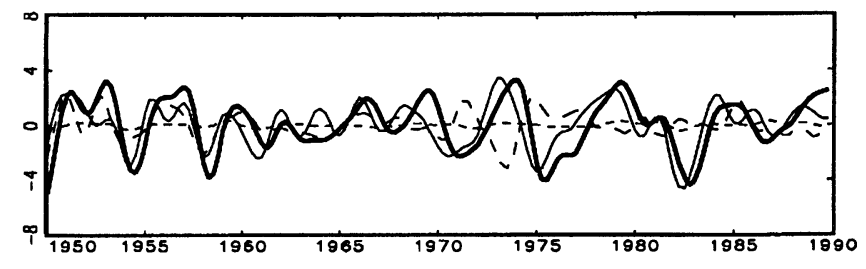

D. Real Balances

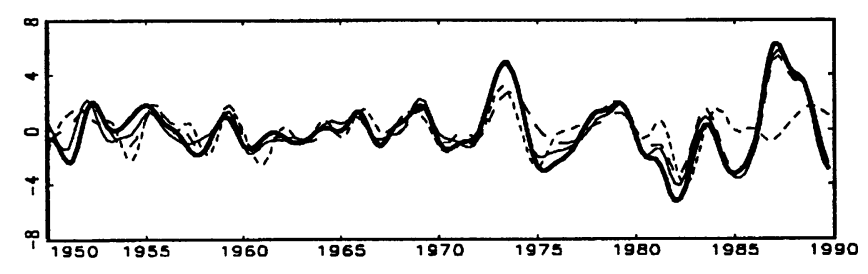

F. Real Interest Rates

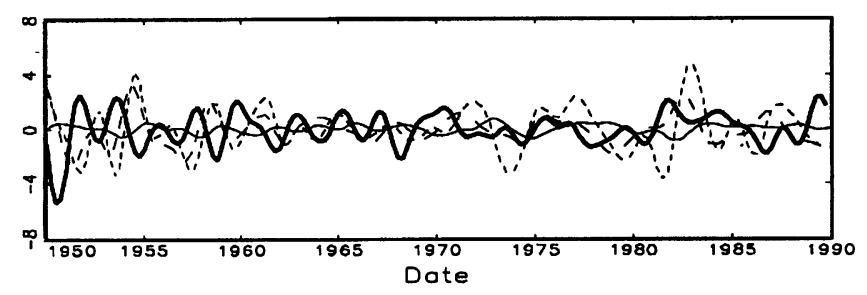

Note: Each panel shows the 6-32 quarter bandpass filtered series for postwar quarterly U.S. data (thick line), the real business cycle model (thin line), the sticky-price model (long dashes), and the financial market frictions model (short dashes).

$y, c, i, n$ and $r$, the results for the baseline liquidity effect (LE) model are very close to what one obtains from the RBC model with the same investment cost parameter $(\eta=1)$. The reason is that there are very small "multipliers" attached to the effect of nominal money on real economic activity, despite the presence of liquidity effects, so that the spectra are essentially those of the RBC model (i.e., nearly all of the variability in the variables is produced by productivity shocks). Indeed, when the model is solved using money as the only driving process, the cyclical standard deviation of output falls from 1.6 to 0.1 (see row 11 of table 3, panel B). The only real variable with different behavior in the RBC $(\eta=1)$ and LE models (with productivity shocks) is the wage rate $w$, which is more variable in the LE model. The increased variability can be traced to the variability in nominal interest rates, which affects labor demand in this model, as discussed in section III.

The comovement of real activity and nominal variables stems from a surprising source in the liquidity effect model. Because the causal role of monetary shifts on output is small (money is close to neutral in our parameterization of the model), essentially all of the correlation between money and output arises from the assumed correlation of money and productivity. To see this, note that the baseline version of the model does capture the cyclical correlation of money and output: $\operatorname{cor}\left(M_{t}, y_{t}\right)=0.65$ in panel A of table 3 . However, this correlation falls to 0.06 when the money and pro- ductivity processes are assumed to be independent (row 10 of panel B of table 3).

The cyclical behavior of the price level is also very reminiscent of that found in the real business cycle model. $P$ and $y$ are negatively correlated contemporaneously, as in the data. However, there is not a quantitatively important inverted leading indicator relationship predicted by the LE model, in contrast to the RBC model.

However, the financial market frictions model does not inherit the problems that the RBC model has in capturing the contemporaneous relationship between real interest rates and output for two reasons. First and most important, like the sticky-price model, our LE model has high investment adjustment costs. Secondly, the real interest rate and output are negatively associated for the small part of output that is attributable to the non-neutral effects of monetary shocks (see row 11 of panel B). However, the LE model does not produce a real interest rate that is an inverted leading indicator: it implies that $\operatorname{cor}\left(r_{t}, y_{t+4}\right)=0.50$, while in the data $\operatorname{cor}\left(r_{t}, y_{t+4}\right)=-0.41$.

Moreover, the LE model produces an altered pattern of correlations of nominal interest rates with output that eliminates the success that the RBC model had in matching these correlations. It implies that the nominal rate should be negatively associated with output contemporaneously and should be a positive leading indicator; the data display a positive contem- 
poraneous association and an inverted leading indicator role for the nominal rate. ${ }^{19}$

\section{Explaining Postwar Business Cycles}

Figure 5 shows fitted values for selected series from each of the three models for the postwar U.S. data. (Results for all of the variables are plotted in King and Watson (1993a).) These fitted values were obtained by solving the models using the data's VAR residuals for $\xi_{t}$ in equation (15). The resulting fitted values were then filtered to highlight their business cycle components using the same bandpass filter used to produce figure 2 .

Figure 5 reinforces many of the conclusions reached above. First, the fitted values for the RBC model closely match the data; this is less true for the other two models, where the fitted values are less variable than the data. The same result was evident from the spectrum. Employment is essentially constant over the cycle in the liquidity effect model, again a result that was evident from the spectrum. Employment in the sticky-price model has significant cyclical variation, but its large cyclical swings are sometimes opposite of those in the data (see 1970-76). This results from the negative effect of productivity shocks on employment in this model. Interestingly, the fitted values for prices match the data more closely in the RBC model than in the other two models. Prices from the sticky-price model are too smooth over the business cycle; prices in the liquidity effect model have the right overall variability, but the correlation with the data is not as high as in the RBC model. In particular, the liquidity effect model predicts large movements in prices in the late 1980 s were associated with the large increases in money. This doesn't occur in the RBC model: the increase in real balances in the late 1980s is associated with lower than average nominal interest rates in the model. Finally, all of the models do very poorly matching both real and nominal interest rates. There is little relation between the data and the fitted values of interest rates from any of the models.

\section{Summary and Conclusions}

Our results are usefully divided into two categories. The first set concerns the ability of the various models to capture measures of variability, such as the empirical spectral shapes of growth rates for various real and nominal variables. The second set concerns the ability of the models to

\footnotetext{
${ }^{19}$ It is perhaps useful to note that the model with just monetary shocks (line 11 of panel B of table 3) does capture some of the lead-lag relations evident in the data, even though the size of the real multipliers on money in the model are very small. For example, when the model is solved using money as the only driving process, real interest rates are countercyclical and do lead output somewhat (cor $\left(r_{t}, y_{t}\right)=-0.42$ and cor $\left(r_{t}, y_{t+1}=-0.48\right)$. Similarly, money is procyclical and slightly leading $\left(\operatorname{cor}\left(M_{t}, y_{t}\right)=0.76\right.$ and cor $\left.\left(M_{t}>y_{(t+1)}\right)=0.78\right)$. However, this version of the model predicts that there should be a pattern of correlations between nominal interest rates and output that is very different from that found in the data.
}

capture the covariation of money, interest rates and prices with the business cycle.

In terms of variability, we find that the real business cycle model can capture the spectral shapes of many real and nominal variables, but only when it is driven by a highly volatile "Solow residual" whose growth rate itself has the typical spectral shape. The sticky-price model also can match the typical spectral shape; it does so in part because highly persistent monetary shocks have only a temporary impact on output. However, our version of the sticky-price model relies on an underlying "monopolistic competition" framework which dictates that productivity is less cyclically volatile than measured Solow residuals. This smaller volatility of shocks, coupled with demand-side determination of output in the short run, implies that the sticky-price model generates less business cycle variability than is present in the data or in the real business cycle model. Both the sticky-price and real business cycle models produce too little business cycle variation in real interest rates.

We also find that the liquidity effect model can also generate the typical spectral shape of growth rates, but this outcome is subject to three important qualifications. First, the model works much like a version of the standard real business cycle model, but one that predicts only small cyclical variation in labor input in response to both monetary and productivity shocks. It thus displays much less real volatility than the other models. Second, business cycle variability produced by the model is almost entirely due to real rather than monetary shocks. Finally, the model produces too much volatility in real interest rates.

In terms of covariability, the three models have very different abilities to match the core facts and all have some substantial difficulties in this regard, particularly with respect to interest rates. ${ }^{20}$ The real business cycle model with endogenous money has some modest success in capturing the comovements between nominal indicators and the business cycle. It captures the covariation of output and the money stock well, although this occurs because money and productivity shocks are assumed to be highly correlated. It also successfully captures the contemporaneous negative correlation of the price level with real activity, despite a substantial procyclicality of the money stock. The model does a good job capturing the dynamic interaction of the nominal interest rate with real activity (although with a correlation that is smaller than that in the U.S. data). Finally, it predicts that the price level will be an (inverted) leading indicator. However, the RBC model displays a dismal performance in terms of real interest rates: it predicts that the real interest rates should be a positive leading indicator for real activity,

\footnotetext{
${ }^{20}$ Sims (1994) also highlights some interest rate puzzles that arise in commonly employed macroeconomic models. In contrast to our work, Sims focuses mainly on the implications that alternative models have for the expected time paths of money, interest rates, prices and real activity given alternative schemes for identifying policy and other shocks.
} 
while the empirical finding is that real interest rate increases lead output decreases.

The sticky-price model also has some success in capturing core patterns of real and nominal interactions, but it is also deficient in a number of important ways. In terms of successes, it surprisingly predicts that the price level should be negatively correlated with real activity contemporaneously and with a year lead. (This negative contemporaneous correlation stems in large part from the effect of productivity shocks.) It also captures the modest, negative contemporaneous correlation between the real rate and output. But there are many other deficiencies. Notably, the sticky-price model suggests a high real or nominal interest rate in the current quarter should be a strong signal of high future economic activity, while opposite signal is indicated by the data. This lack of an inverted leading indicator role for interest rates is particularly surprising since our sticky-price model predicts that nominal and real rates should be strongly negatively correlated contemporaneously with real output.

In terms of matching the cyclical covariation of money, interest rates and the price level, the financial market frictions model has a core difficulty: it predicts that real activity is not very responsive to nominal money - there are small "multipliers" attached to nominal shocks - and it predicts that real and nominal interest rates are highly volatile in response to these factors. Consequently, the cyclical covariation of money and economic activity comes primarily from the same source as in the real business cycle model, the assumed correlation between the money and productivity processes. In terms of the price level, the model captures a countercyclical response of the price level to output (which results from the dominant role of productivity shocks) but cannot capture the inverted leading indicator role of the price level. While the model does capture the modest negative correlation of the real rate with output, it does so only by also predicting that the nominal rate is negatively correlated with output (a counterfactual implication that it shares with the sticky-price model). Finally, like the other two models, the liquidity effect model misses the "negative leading indicator" role of the real interest rate.

Overall, we conclude that all prominent macroeconomic models - those which stress a single set of economic mechanisms-have substantial difficulties matching the core features of nominal and real interactions. Most strikingly, all of the models do a poor job at matching the interaction of real and nominal interest rates with real activity. More generally, our paper documents the diverse successes and failures of these models. By doing so, it suggests that new models, which incorporate new mechanisms or combine existing mechanisms, will be necessary to explain the main empirical linkages between money, prices, interest rates and the business cycle.

\section{REFERENCES}

Ball, L., and Gregory Mankiw, “A Sticky-Price Manifesto," Carnegie-Rochester Series on Public Policy 41 (1994), 127-151.

Barro, Robert J., and H. I. Grossman, Money, Employment and Inflation (Cambridge: Cambridge University Press, 1976)

Baxter, Marianne, and Robert King, "Measuring Business Cycles: Approximate Bandpass Filters for Economic Time Series," National Bureau of Economic Research Working Paper No. 5022 (Feb. 1995).

Berk, Kenneth D., "Consistent Autoregressive Spectral Estimators," Annals of Statistics 2(3) (1974), 489-502.

Beveridge, Stephen, and Charles Nelson, "A New Approach to Decomposition of Time Series into Permanent and Transitory Components with Particular Attention to the Measurement of the 'Business Cycle'," Journal of Monetary Economics 7 (1980), 151-177.

Blanchard, Olivier J., and C. Kahn, "The Solution of Linear Difference Models Under Rational Expectations," Econometrica 48 (1980), 1305-1312.

Burns A., and W. Mitchell, Measuring Business Cycles (New York: National Bureau of Economic Research, 1947).

Calvo, G. A., "Staggered Prices in a Utility-Maximizing Framework," Journal of Monetary Economics 12 (1983), 383-398.

Campbell, J. Y., and N. Gregory Mankiw, "Are Output Fluctuations Transitory?" Quarterly Journal of Economics 102 (1987), 857-880.

Chirinko, Robert S., "Business Fixed Investment Spending: A Critical Survey of Modeling Strategies, Empirical Results and Policy Implications," Journal of Economic Literature 31 (1993).

Christiano, Lawrence J., and Martin Eichenbaum, "Liquidity Effects and the Monetary Transmission Mechanism," American Economic Review 82 (1992), 346-353.

, "Liquidity Effects, Monetary Policy and the Business Cycle," Journal of Money, Banking and Credit, forthcoming.

Cochrane, John H., "How Big Is the Random Walk in GNP?" Journal of Political Economy 96 (1988), 893-920.

,"Permanent and Transitory Components of GNP and Stock Prices," Quarterly Journal of Economics 109 (Feb. 1994), 241-266.

Fama, Eugene F., "Transitory Variation in Investment and Output," Journal of Monetary Economics 30 (1992), 467-480.

Fischer, Stanley, "Long-term Contracts, Rational Expectations and the Optimal Money Supply Rule," Journal of Political Economy 85 (1977), 191-205.

Granger, C. W. J.,"The Typical Spectral Shape of an Economic Variable," Econometrica 34 (1966), 150-161.

Gray, J., "On Indexation and Contract Length," Journal of Political Economy 86 (1978), 1-18.

Hall, Robert E., "The Relation between Price and Marginal Cost in U.S. Industry," Journal of Political Economy 96 (1988), 921-947.

Handbook of Cyclical Indicators, U.S. Department of Commerce (Washington, D.C.: U.S. Government Printing Office,1984).

King, Robert G., "Money and Business Cycles," Journal of Monetary Economics (forthcoming in 1996).

King, Robert G., C. I. Plosser and S. T. Rebelo, "Production, Growth and Business Cycles: I. The Basic Neoclassical Model," Journal of Monetary Economics 21(1988a) 195-232. , "Production, Growth and Business Cycles: II. New Directions," Journal of Monetary Economics 21 (1988b) 309-342.

King, Robert G., Charles I. Plosser, James H. Stock and Mark W. Watson, "Stochastic Trends and Economic Fluctuations," American Economic Review 81 (1991), 819-840.

King, Robert G., and Mark W. Watson, "Money, Prices, Interest Rates and the Business Cycle," Federal Reserve Bank of Chicago working paper, (1995a).

, "The Solution of Singular Linear Difference Equations Under Rational Expectations," manuscript, the University of Virginia (1995b). 
, "System Reduction and Solution Algorithms for Singular Linear Difference Systems Under Rational Expectations," manuscript, the University of Virginia (1995c).

, "Timing Models," manuscript, the University of Virginia (1995d).

Kydland, Finn E., and Edward C. Prescott, "Time to Build and Aggregate Fluctuations," Econometrica 50 (1982), 1345-1370.

Lucas, Robert E., "Money Demand in the United States: A Quantitative Review," Carnegie-Rochester Conference Series on Public Policy 29 (1988), 137-168.

, "Liquidity and Interest Rates," Journal of Economic Theory 50 (1990), 237-264.

Nelson, Charles R., and Charles I. Plosser, "Trends and Random Walks in Macroeconomic Time Series," Journal of Monetary Economics 10 (1982), 139-162.

Phelps, Edmund, and James B. Taylor, "Stabilizing Powers of Monetary Policy Under Rational Expectations," Journal of Political Economy 85(1) (Feb. 1977), 163-190.

Rotemberg, James, "Monopolistic Price Adjustment and Aggregate Output," Review of Economic Studies 49 (1982a), 517-531.

, "Sticky Prices in the United States," Journal of Political Economy 90 (1982b),1187-1211.
, “The New Keynesian Microfoundations," NBER Macro Annual (Cambridge, MA: MIT Press,1987),

Rotemberg, James, and M. Woodford, "Is the Business Cycle a Necessary Consequence of Stochastic Growth?" MIT working paper 3653-94-EFA (Feb. 1994).

Sims, Christopher A., "Interpreting the Macroeconomic Time Series Facts," European Economic Review 36 (1992), 975-1011.

Stock, James, and M. Watson, "A Simple Estimator of Cointegrating Vectors in Higher Order Cointegrated Systems," Econometrica 61 (1993), 783-820.

Watson, Mark W., "Univariate Detrending with Stochastic Trends," Journal of Monetary Economics 18 (1986), 49-75.

, "Measures of Fit for Calibrated Models," Journal of Political Economy 101(1993), 1011-1041.

Yun, Tack, "Nominal Price Rigidity, Money Supply Endogeneity, and Business Cycles," Journal of Monetary Economics (forthcoming 1996).

Zarnowitz, Victor, "Corporate Bond Prices as a Leading Indicator," in G. Moore (eds.), A Review of the Leading, Coincident and Lagging Indicators, Center for International Business Cycle Research, Columbia Business School (1988).

Zarnowtiz, Victor, and C. Boschan, "Cyclical Indicators: An Evaluation and New Leading Indexes," Business Conditions Digest (May 1975). 